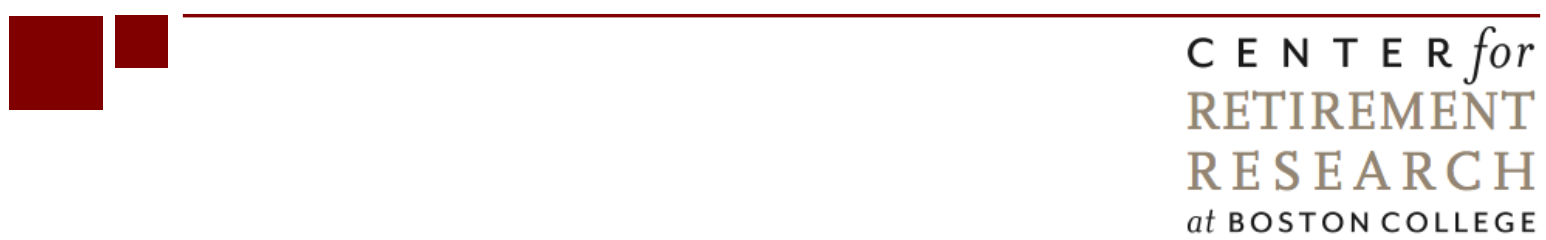

\title{
HOUSING IN RETIREMENT ACROSS COUNTRIES
}

\author{
Makoto Nakajima and Irina A. Telyukova \\ CRR WP 2013-18 \\ Submitted: July 2013 \\ Released: August 2013
Center for Retirement Research at Boston College
Hovey House
140 Commonwealth Avenue
Chestnut Hill, MA 02467 \\ Tel: 617-552-1762 Fax: 617-552-0191 \\ http://crr.bc.edu
}

Makoto Nakajima is a senior economist at the Research Department of the Federal Reserve Bank of Philadelphia. Irina A. Telyukova is an assistant professor in the Department of Economics at the University of California, San Diego. The research reported herein was pursuant to a grant from the U.S. Social Security Administration (SSA), funded as part of the Retirement Research Consortium (RRC). The findings and conclusions expressed are solely those of the authors and do not represent the views of SSA, any agency of the federal government, the RRC, the Federal Reserve Bank of Philadelphia, the University of California, San Diego, or Boston College. The authors would like to thank 2012 SED Meetings and the NBER Summer Institute EFACR Group participants for their feedback.

(C) 2013, Makoto Nakajima and Irina A. Telyukova. All rights reserved. Short sections of text, not to exceed two paragraphs, may be quoted without explicit permission provided that full credit, including (C) notice, is given to the source. 


\begin{abstract}
About the Steven H. Sandell Grant Program
This paper received funding from the Steven H. Sandell Grant Program for Junior Scholars in Retirement Research. Established in 1999, the Sandell program's purpose is to promote research on retirement issues by scholars in a wide variety of disciplines, including actuarial science, demography, economics, finance, gerontology, political science, psychology, public administration, public policy, sociology, social work, and statistics. The program is funded through a grant from the Social Security Administration (SSA). For more information on the Sandell program, please visit our website at: http://crr.bc.edu/about-us/grantprograms/stevenhsandell-grant-program-2/ send e-mail to crr@bc.edu, or call (617) 552-1762.
\end{abstract}

\title{
About the Center for Retirement Research
}

The Center for Retirement Research at Boston College, part of a consortium that includes parallel centers at the University of Michigan and the National Bureau of Economic Research, was established in 1998 through a grant from the Social Security Administration. The Center's mission is to produce first-class research and forge a strong link between the academic community and decision-makers in the public and private sectors around an issue of critical importance to the nation's future. To achieve this mission, the Center sponsors a wide variety of research projects, transmits new findings to a broad audience, trains new scholars, and broadens access to valuable data sources.

\author{
Center for Retirement Research at Boston College \\ Hovey House \\ 140 Commonwealth Avenue \\ Chestnut Hill, MA 02467 \\ phone: 617-552-1762 fax: 617-552-0191 \\ e-mail: crr@bc.edu \\ crr.bc.edu
}

Affiliated Institutions:

The Brookings Institution

Massachusetts Institute of Technology

Syracuse University

Urban Institute 


\begin{abstract}
The "retirement saving puzzle" in the literature is a phenomenon in which many U.S. households have significant wealth late in life, contrary to the predictions of a simple life-cycle model. In this project, we examine cross-country differences in the saving behavior of retirees in order to weigh in on the discussion of the puzzle. First, we find that countries in our sample vary noticeably in terms of the extent of the puzzle: one group of countries, in South and Central Europe, look like the United States, while in Northern Europe, retirees spend down their wealth much more rapidly. Second, it appears that the rate of dissaving in retirement is correlated with the extent of public coverage of healthcare and long-term care, and these differences in saving happen predominantly through dissaving of financial assets, while housing assets are less affected. In a quantitative experiment using a life-cycle model of saving in retirement, we measure the role of out-of-pocket medical spending risk in accounting for differences in observed saving patterns among retirees in the United States and Sweden, considering housing and financial assets separately. The model predicts that this risk accounts, on average across age, for one-half of the difference in median net worth between United States and Sweden, and for about 70 percent of the difference in median financial assets. The role of risk diminishes with age, and is seen primarily in financial asset saving, while housing assets do not appear to respond to spending risk, suggesting that housing is not a precautionary asset.
\end{abstract}




\section{Introduction}

In the United States, households have, on average, significant positive wealth late in life. In the Health and Retirement Study, median net worth of a household at age 90 was about $\$ 75,000$ in 2006 . The large literature on the subject, sometimes referred to as the retirement saving puzzle (RSP), has studied a number of possible explanations for why retirees do not spend down wealth quickly, which have included longevity risk, bequest motives, precautionary motives and medical expense risk, and public care aversion.

Most authors in the literature study net worth of retirees. Instead, Nakajima and Telyukova (2012) show that housing plays a major role in saving patterns of retirees, and that once illiquidity of housing, relative to financial assets, is taken into account in a structural model of life-cycle saving, it changes previous conclusions about the relative roles of risk, bequests and other factors in explaining saving behavior late in life. ${ }^{1}$. This result suggests that in order to understand the retirement saving puzzle fully, housing assets need to be studied separately from financial assets. Nakajima and Telyukova (2012) also show, as other authors have done, that in the class of models often used in the literature, it is difficult to identify relative strengths of bequest and precautionary motives based on data from a single country.

In this paper, we aim to quantify the relative importance of these motives by studying, empirically and theoretically, cross-country variation in saving in retirement, distinguishing housing from financial assets. Using household-level data from the U.S., U.K., and ten developed economies in continental Europe, we document cross-sectional age profiles for retirees age 65 and above of net worth, housing and financial assets, as well as homeownership rates and debt. We also document salient differences in institutions in these countries, focusing in particular on the prevalence of out-of-pocket medical expenses and long-term care expenses, housing and mortgage markets, and social safety nets. Then we focus on the significant cross-country differences in risk characteristics of retirement that stem from differing degrees of public coverage of healthcare and long-term care, and study how saving in retirement is affected by these risk differences using a rich life-cycle model of housing and saving in retirement.

For the empirical analysis, we use the U.S. Health and Retirement Study (HRS), the English Longitudinal Study of Ageing (ELSA), and the Survey of Health, Ageing and Retirement in Europe (SHARE). ELSA and SHARE were modeled after, and are harmonized with, the HRS, to characterize the saving behavior of retirees in the U.S., the U.K. and a number of continental European countries. The results of our analysis indicate a clear separation of the countries in our sample into a group where the retirement saving puzzle is pronounced ("high-RSP" countries), i.e. where retirees spend down their wealth slowly as in the U.S., and where it is much less prevalent ("low-RSP" countries), where retirees spend down wealth more quickly. In the high-RSP countries, retirees of age 86-90 still hold on average $65 \%$ of the wealth they

\footnotetext{
${ }^{1}$ The role of housing had previously been studied empirically, e.g. by Venti and Wise (2004)
} 
held at age $65-69$; in the low-RSP countries, this ratio is on average only $21 \%$. There is heterogeneity in patterns across the countries, so to fix ideas, we focus on a comparison of U.S. against Sweden, because Swedish retirees, unlike U.S. ones, have universal coverage of healthcare and long-term care. We find that in Sweden, where retirement is relatively low-risk, retirees decumulate financial assets more quickly than in the U.S., while the age profiles of homeownership and housing assets are quite similar. This suggests that risk of high expenses late in life may affect saving in financial assets, but homeownership and saving in housing are primarily affected by other factors, likely having to do with housing and mortgage markets and bequest motives.

In order to quantify the role of risk in saving in retirement, and its differential role for housing and financial assets, we pose a modified version of the model of life-cycle saving in retirement from Nakajima and Telyukova (2013), where retirees can choose whether to own or rent a house, how much to save in a financial asset, and how much to borrow against their house if they are a homeowner. Model households face health and mortality risk, as well as out-of-pocket medical and long-term-care expense risk. They have a warm-glow bequest motive. The government provides a consumption floor, which in the U.S. captures Medicaid (see De Nardi et al. (2012)).

The question that we answer is how much of the difference in saving between U.S. and Swedish retirees is accounted for by the differences in risk characteristics of retirement across the two countries. We calibrate the benchmark model to match cross-sectional age profiles of net worth, housing and financial assets, homeownership rates, as well as indebtedness rates in the U.S. HRS data. Observable features, such as income, wealth and health distribution at age 65, health and medical expense risk, and housing markets are calibrated exogenously from our household data. We then change the observable features of the environment, particularly having to do with medical and long-term-care expense risk, from the U.S. to Sweden, and compare the resulting optimal age profiles of saving to Swedish data.

The model predicts that this risk accounts, on average across age, for $49 \%$ of the difference in median net worth between U.S. and Sweden, with the number ranging mostly between $7 \%$ and $56 \%$, depending on age. OOP spending risk accounts on average for $68 \% \mathrm{l}$ of the difference in median financial assets, with the range mostly of 22-225\%. The role of risk diminishes with age, and is seen primarily in financial asset saving, while housing assets do not appear to respond to spending risk, thus suggesting that housing is not a precautionary asset. That is, retirees stay in their homes late in life for reasons other than spending risk, which our experiment explicitly holds constant; instead, retirees hedge against the risks they face using their financial assets.

Understanding how household finance their retirement is crucial at a time when policymakers in many countries face aging populations and issues of sustainability of social security policies. Our results highlight 
the importance of separating housing from financial assets in order to understand the motives for saving behavior late in life, because risk, social insurance, bequests and other motives impact different assets differently. Since housing plays a key role in household portfolios of retirees, housing market policies are also important to consider. Our research makes two contributions. First, we provide a new set of facts about saving in retirement across countries. Second, we shed new light on saving motives of retirees using cross-country variation in characteristics of retirement.

Our work is related to several strands of literature. The first is the aforementioned literature that provides explanations for the retirement saving puzzle using data on net worth in retirement. For example, Hurd (1989) studies the role of bequest motives and finds them to be small, Hubbard et al. (1995) find that government-provided social insurance should create a motive to dissave in retirement, Ameriks et al. (2011) study the relative importance of bequest motives and public care aversion for the related annuity puzzle, and De Nardi et al. (2010) emphasize the role of out-of-pocket medical expense risk in motivating the elderly to save, while finding bequest motives unimportant. Lockwood (2012) considers the low demand for long-term care insurance as evidence of the relative importance of bequest motives versus precautionary motives.

In addition, we contribute to the emerging body of work that considers cross-country evidence on household portfolios, particularly among older households. Examples are Angelini et al. (2011), who characterize homeownership throughout the life cycle using the retrospective SHARELife survey, and Christelis et al. (forthcoming), who characterize differences in the composition of entire household portfolios in a previous wave of the data that we use, and decompose the reasons for these differences into influences of institutions versus household characteristics.

In section 2, we discuss the data and document empirical facts about saving in retirement across countries. Section 3 presents major details of the housing markets, healthcare and long-term care provision, and social security systems across countries. We summarize our findings in section 4 . In section 5 we present the model, and calibrate it in section 6. Quantitative results are in section 7. Section 8 concludes.

\section{Facts on Saving in Retirement Across Countries}

\subsection{Data Sources}

We use three household surveys in our analysis. The first is the Health and Retirement Study (HRS), which incorporates a large sample from the Asset and Health Dynamics among the Oldest Old (AHEAD), and which covers the U.S. The second survey is the English Longitudinal Study of Ageing (ELSA), which covers the U.K. Finally, the Survey of Health, Aging and Retirement in Europe (SHARE) covers thirteen other countries, of which we use those that have a sufficient time dimension and sample size, namely Sweden, 
Denmark, Netherlands, Belgium, Germany, Austria, France, Spain, Italy and Greece. All three surveys are biennial and longitudinal: the HRS covers the period 1992-2010, ELSA covers 2000-2010, while SHARE is the newest, and at the time of analysis had two waves, 2004 and $2006 .^{2}$ Because the panel dimension of SHARE is very short, at this point we cannot usefully construct life-cycle analyses of individuals or cohorts in it. Therefore, for easy comparison across countries, and unlike our previous work with the HRS in Nakajima and Telyukova (2012), we will study the 2006 cross-sectional age profiles of the desired variables, keeping in mind that inference can be affected by important composition and cohort effects.

We use the RAND versions of the surveys as the base for our analysis. RAND's versions of ELSA and SHARE are far less extensive than for the HRS. To augment the RAND data, we converted the latest wave of ELSA into RAND format, as well as added a significant amount of raw information from these surveys, incorporating them into a comparable data set. For the most part, a direct comparison of the data is possible, upon conversion of currencies into 2000 dollars using real exchange rates and PPP adjustment. Compared to the HRS, a central weakness, from our perspective, of both ELSA and SHARE is the insufficient documentation of respondents who are in nursing homes. Relative to outside data that we have, SHARE understates significantly the percentage of people in nursing homes, while ELSA did not interview respondents in institutions. We will address these issues further below, where relevant.

In constructing the age profiles, we stop at age 90. The reason is that the SHARE data set has fairly small country sample sizes, and unlike HRS, it does not oversample the oldest old. As a result, the sample sizes of the oldest retirees get too small to construct reliable moments. In addition, to smooth noise in the data, in all the surveys, we put households into 5-year centered age bins, so that age 65 is actually a bin of ages 63-67. Thus, each household is categorized into five different age groups, of its actual age, as well as minus/plus two years.

\subsection{Data Facts, All Countries}

Figure 1 shows how we divide the countries in our sample into two categories. In the left panel are countries where the age profiles of median net worth are relatively flat, that is, where retirees are slow to spend down wealth. For example, in the U.S., median net worth at age 90 is about $\$ 100,000$, while it is around $\$ 200,000$ for the UK and Belgium. The full group of countries includes the U.S. and the U.K., as well as Spain, Greece, France, Belgium and Italy. As shorthand, we term these countries "high-RSP" countries, for the high prevalence of the retirement saving puzzle. In these countries, median net worth of retirees at age $86-90$ is on average $65 \%$ of median net worth at age $65-69$.

The right panel of figure 1 shows countries where in the median, net worth is spent down much more

\footnotetext{
${ }^{2}$ The third wave of SHARE, known as SHARELife, came out in 2008 and constructs life-cycle data from restrospective surveys; we do not use this wave, as it is quite different from the other two.
} 

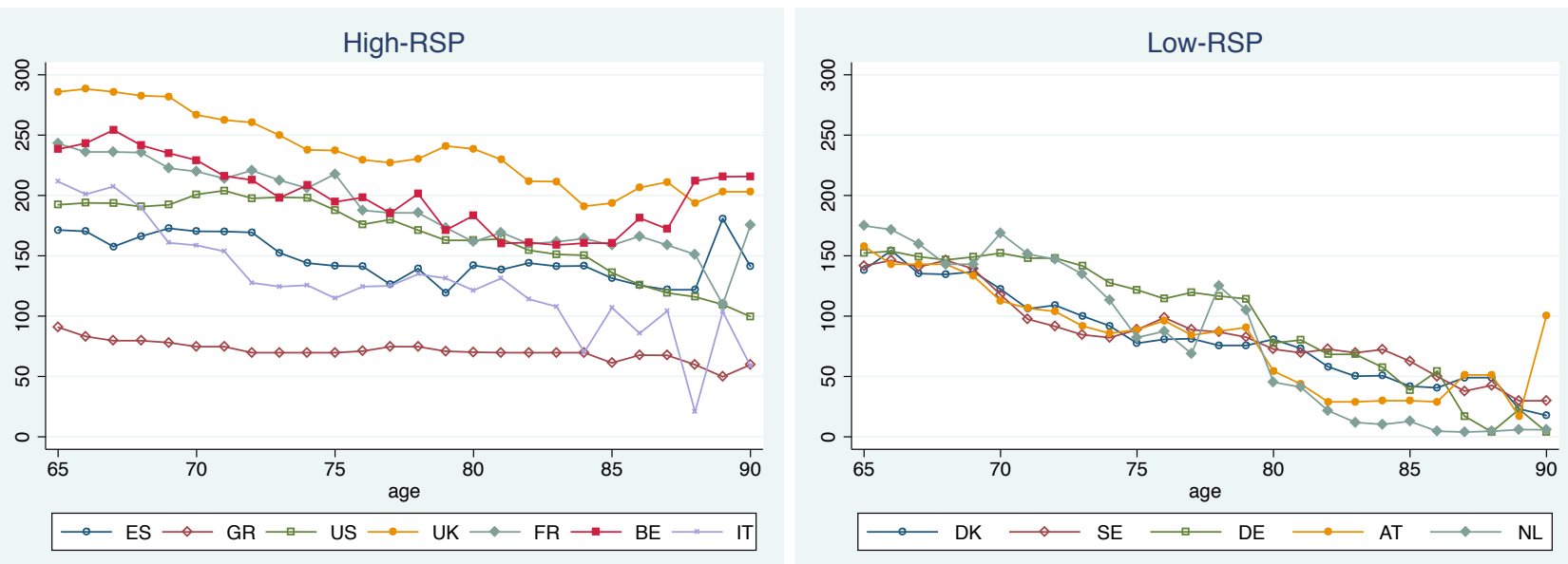

Figure 1: Age Profiles of Median Net Worth. Thousands PPP-Adj. 2000 U.S. \$.
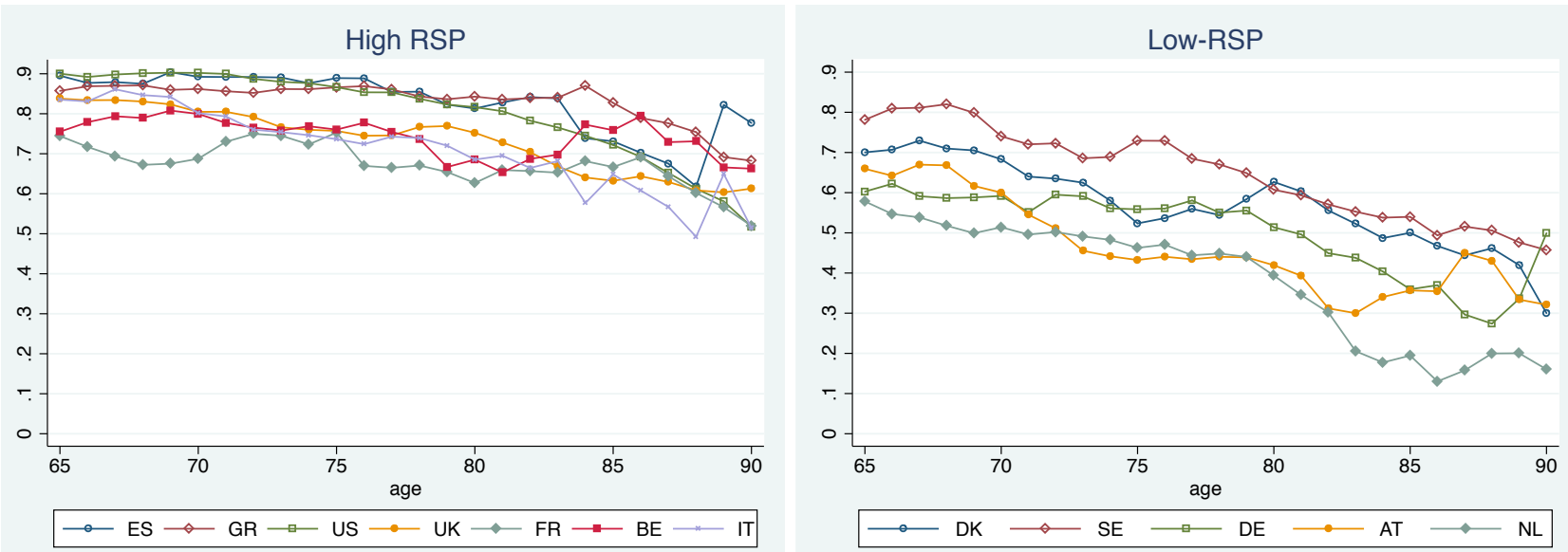

Figure 2: Homeownership Rates

quickly with age. For example, in the Netherlands, Germany and Denmark, net wealth appears to decline close to zero in the median. The countries in the "low-RSP" group are Denmark, Sweden, Germany, Austria and the Netherlands. The average ratio of median net worth at age 86-90 to median net worth at age 65-69 is just $21 \%$ in these countries.

Figure 2 presents homeownership rates among retirees for the countries in the two groups, defined as percent of the age group that own homes. In high-RSP countries, homeownership rates are on average higher at age 65, and remain high until age 90 . The median retiree in these countries at age 90 is a homeowner. In low-RSP countries, retirees start with a lower ownership rate, and in some countries sell houses at a faster rate. Partly due to lower ownership overall, the median age-90 retiree in these countries is a renter. For example, in the U.S. the homeownership rate is about $90 \%$ at age 65 and is still above 

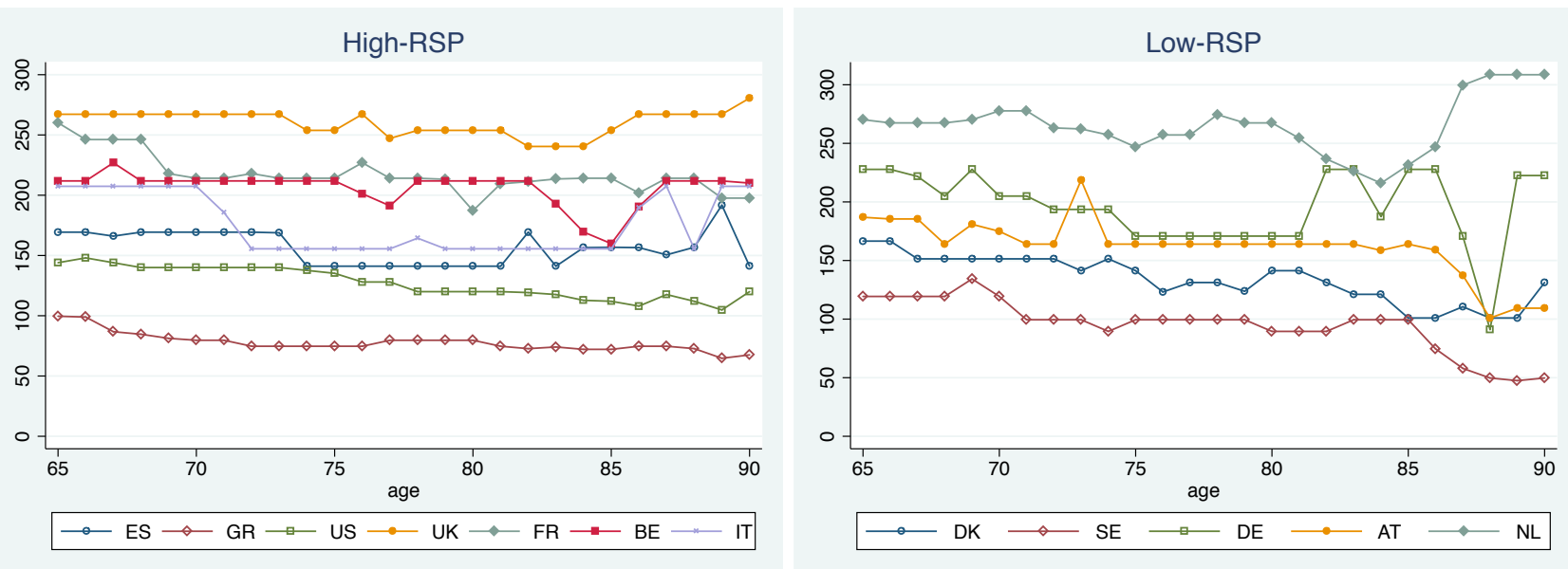

Figure 3: Age Profiles of Median Housing Assets. Thousands 2000 U.S. \$.
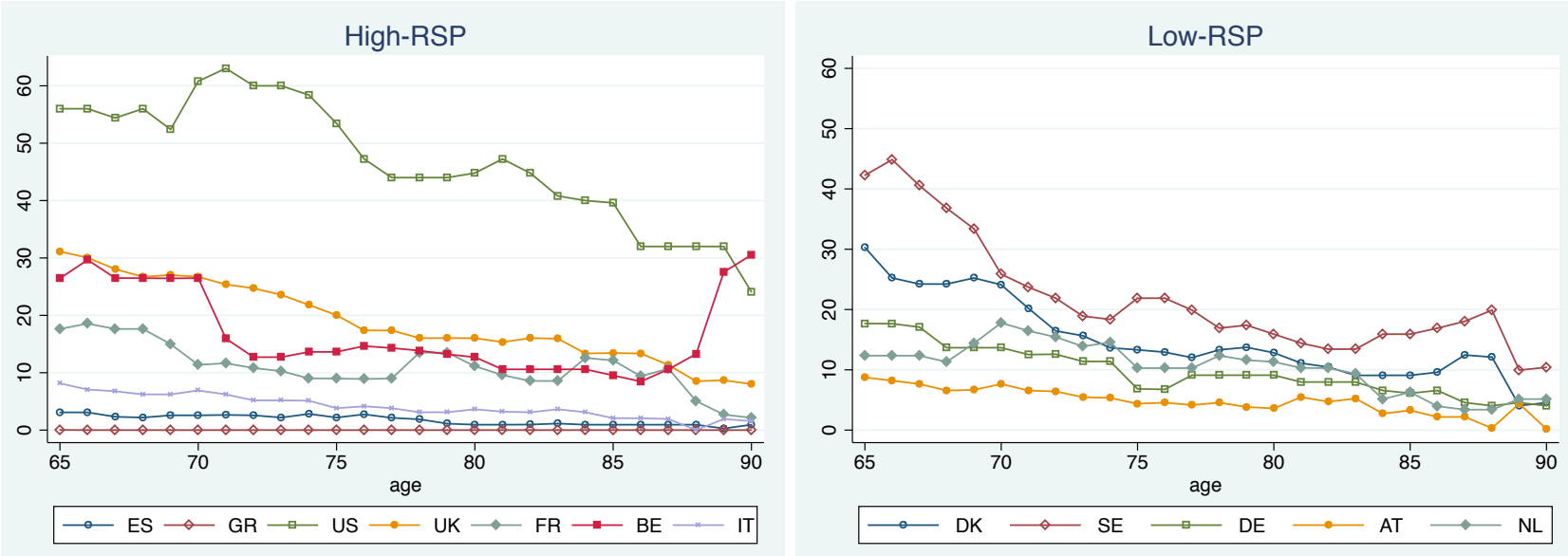

Figure 4: Age Profiles of Median Financial Assets. Thousands 2000 U.S. $\$$.

$50 \%$ at age 90 . In Sweden, the rates are not dissimilar: they decline from just under $80 \%$ to about $45 \%$. Instead, in the Netherlands, that decline is from near $60 \%$ to below $20 \%$.

Notice, however, that in all the countries, homeownership rates remain high and positive late in life; even in low-RSP countries, at age 90, homeownership rates are 20-50\%. This is an important aspect of saving late in life, and will be one of the facts that we will aim to account for using our model.

We next break down the assets of retirees into housing and financial assets, respectively, in figures 3 and 4. The median housing asset age profiles look remarkably similar in all the countries, in that they are flat with age. The profiles of financial wealth are varied in terms of level and slope, but on average, there is more rapid spend-down of financial wealth in low-RSP countries, in most countries close to zero. It is also notable that U.S. retirees hold by far the most financial wealth, both at the beginning and at the end 

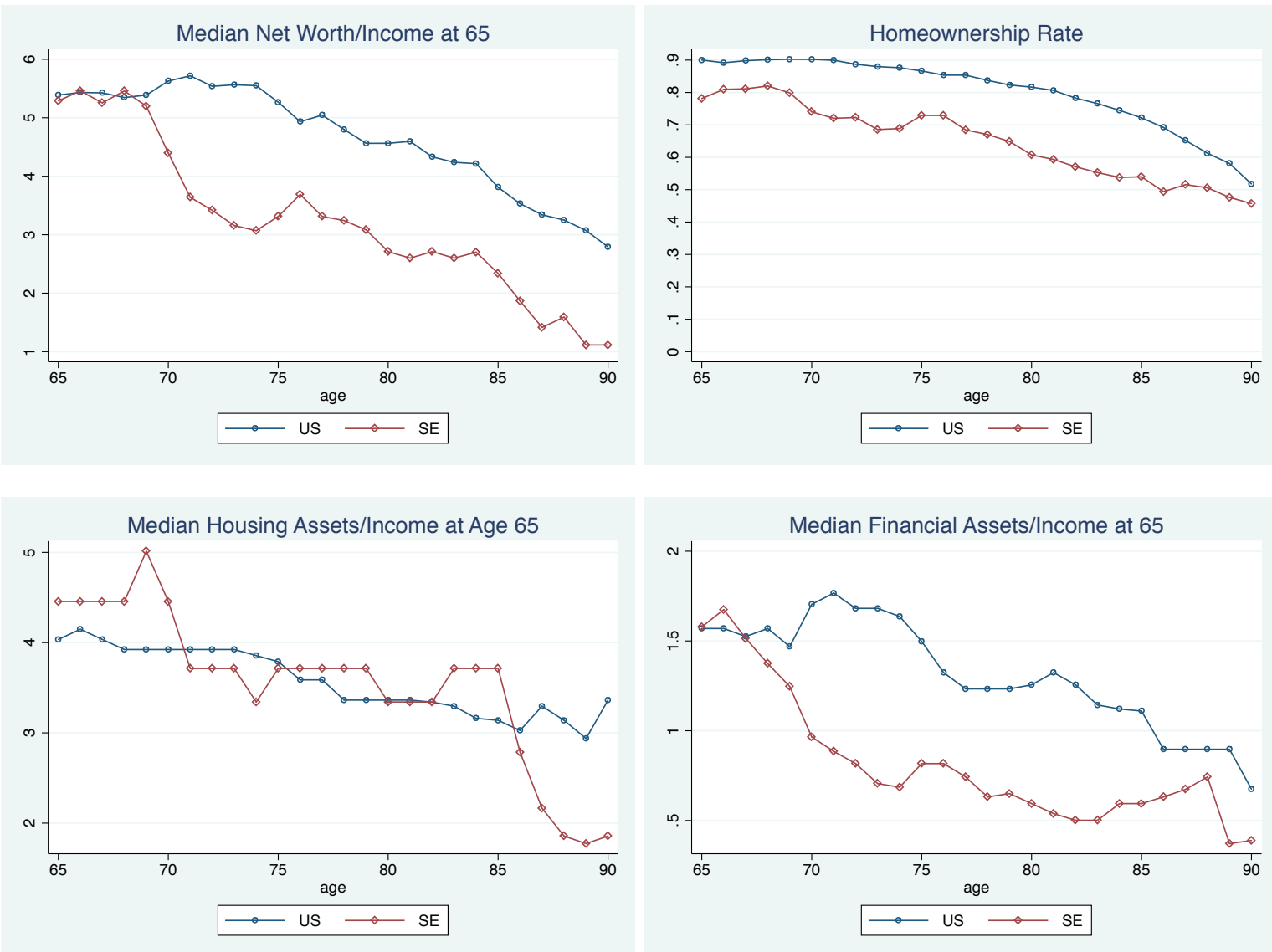

Figure 5: Age Profiles, U.S. vs Sweden. Thousands PPP-Adj. 2000 U.S. \$.

of retirement.

It appears that insofar as there are differences between the countries in the two groups, in terms of decumulation of net worth, they are expressed in faster spend-down of financial assets and possibly faster liquidation of housing, while median housing profiles among homeowners are generally flat, conditional on ownership, and homeownership is significant late in life in most countries.

\subsection{Case Study: U.S. and Sweden}

To fix ideas further, in the remainder of our empirical section, and for our experiments, we will focus on the case of two countries that represent the two groups: U.S. and Sweden. We choose Sweden because it allows us to control for major variation in initial conditions at retirement: Sweden is similar to the U.S. in terms of initial wealth of retirees at age 65 , and in terms of homeownership rates. In addition, as we will discuss below, Swedish law, unlike the U.S., provides universal - i.e. not means-tested - coverage of healthcare and long-term care, which are two major sources of expense risk late in life of U.S. retirees.

For this analysis, in order to control for cross-country income differences, we normalize all wealth 

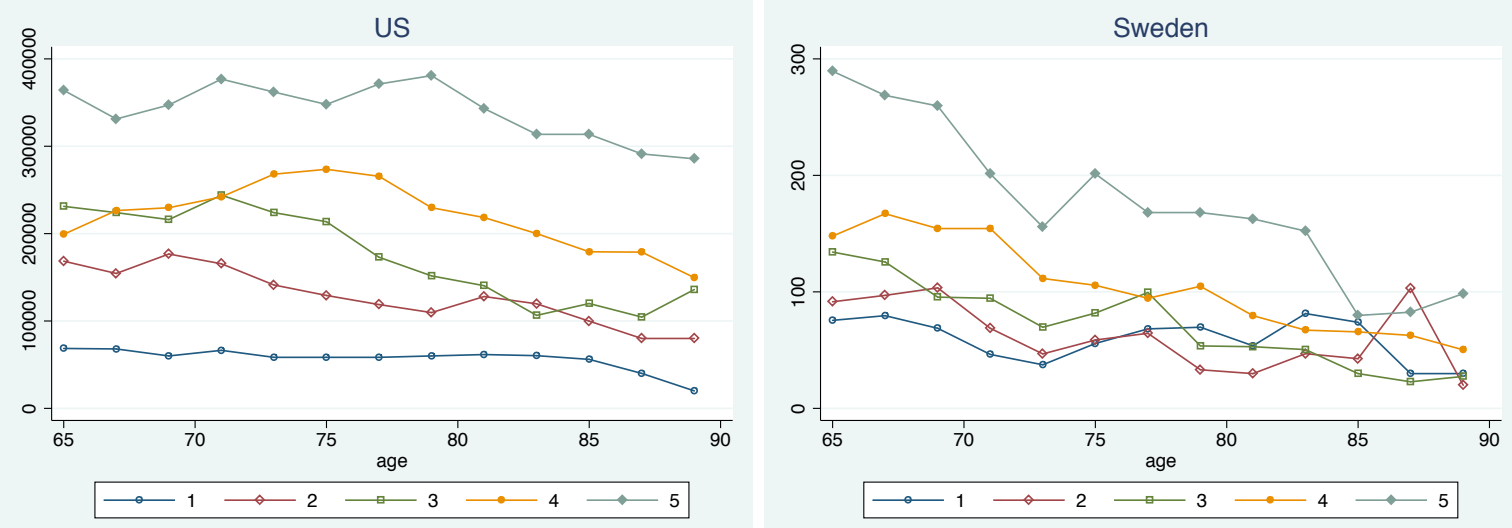

Figure 6: Net Worth by Income Bin, U.S. vs Sweden. Thousands PPP-Adj. 2000 U.S. $\$$.
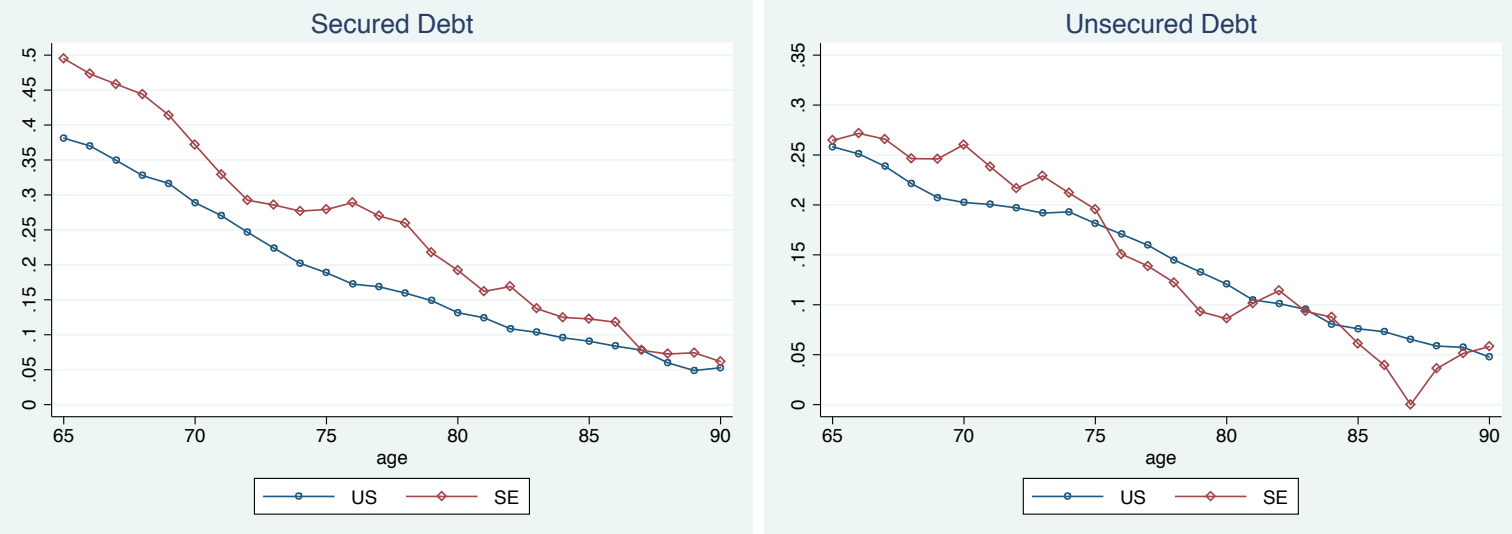

Figure 7: Age Profiles of Debt Rates, U.S. vs Sweden.

variables by average income of the age- 65 group. Figure 5 shows median net worth, housing and financial assets normalized by income, as well as the homeownership rate for the two countries. It is clear from this comparison that decumulation of wealth is much more rapid in Sweden than it is in the U.S., and that the difference in spenddown behavior is particularly observable in financial assets. Instead, homeownership rates are close in the two countries, and decline at similar rates with age, and conditional median housing profiles are remarkably similar in the two countries and show only a moderate decline.

We examine the wealth distribution among retirees in the two countries in figure 6 . Wealth dispersion is higher in the U.S. throughout the retirement life cycle. In all quintiles of the distribution, net worth in the U.S. is flat with age, not showing significant decumulation; in all but the bottom quintile, net worth is positive late in life. Instead, in Sweden wealth dispersion is smaller at age 65, and declines relative to the U.S. by age 90. Decumulation of wealth is present in all quintiles, but it is particularly visible in the top quintile. 
Finally, figure 7 shows that the rates of indebtedness in the two countries are similar, both in terms of secured or home equity debt, and unsecured debt.

\section{Institutions}

\subsection{Out-of-Pocket Medical and Long-Term Care Expenses}

Previous work on saving in retirement has identified out-of-pocket (OOP) medical and long-term care expense risk a significant potential source of risk in retirement, which, in addition to longevity risk, may be capable of accounting for the patterns of saving in retirement in the U.S. (e.g. De Nardi et al. (2010)). Unlike in the U.S., medical care across Europe tends to be insured by some combination of governmentprovided and mandatory private insurance (WHO, Allin et al. (2005)). There is wide variation in co-pay structures and the extent to which the population participates in private health insurance schemes, but it appears that out-of-pocket expenses are limited in all of the countries in our sample except for the U.S. We are able to measure OOP medical expenses in our sample and discuss this below. Details of healthcare coverage in our sample countries are in Appendix A.1.

As has been pointed out in the literature before (Brown and Finkelstein (2011)), there is a lot more variation in long-term care coverage, and many countries do not have universal coverage for long-term care in the same way that they do for healthcare. Based on our reading of the literature to date (e.g. OECD (2005)), we can classify European countries into three groups. Group (A) provides public coverage of longterm care, both in nursing homes and in-home care, and requires no means-testing and no OOP expenses. This group includes Sweden, Netherlands, Denmark, and Norway (the last is not in our sample). Group (B) provides significant public coverage of long-term care, but does require some OOP expenses, although these expenses are capped at a relatively low level. This group includes Austria and Germany. Finally, group (C) are countries where there is no or low public coverage of long-term care, with means testing and high OOP expenses. This group includes Spain, U.K., U.S. as well as Switzerland (not presented). Notice that in groups (A) and (B), there is no dependence on assets in qualifying for long-term care benefits, while in group (C), such dependence exists. The details of coverage in these countries are in Appendix A.2.

In all of our data except ELSA, we can observe OOP medical and long-term care expenses directly (that is, OOP expenses on prescription drugs, doctor visits, hospital stays and nursing homes). The HRS does the best job of measuring them, while SHARE may present measurement issues because the coverage of institutionalized population is not comprehensive (more on this below, in the Calibration section). ELSA does not measure OOP medical expenses because the National Health System at present makes them zero for all participants, and ELSA does not interview respondents in nursing homes. Based on the HRS and SHARE, we estimate expected mean medical expenses for all countries in our sample except the U.K., 

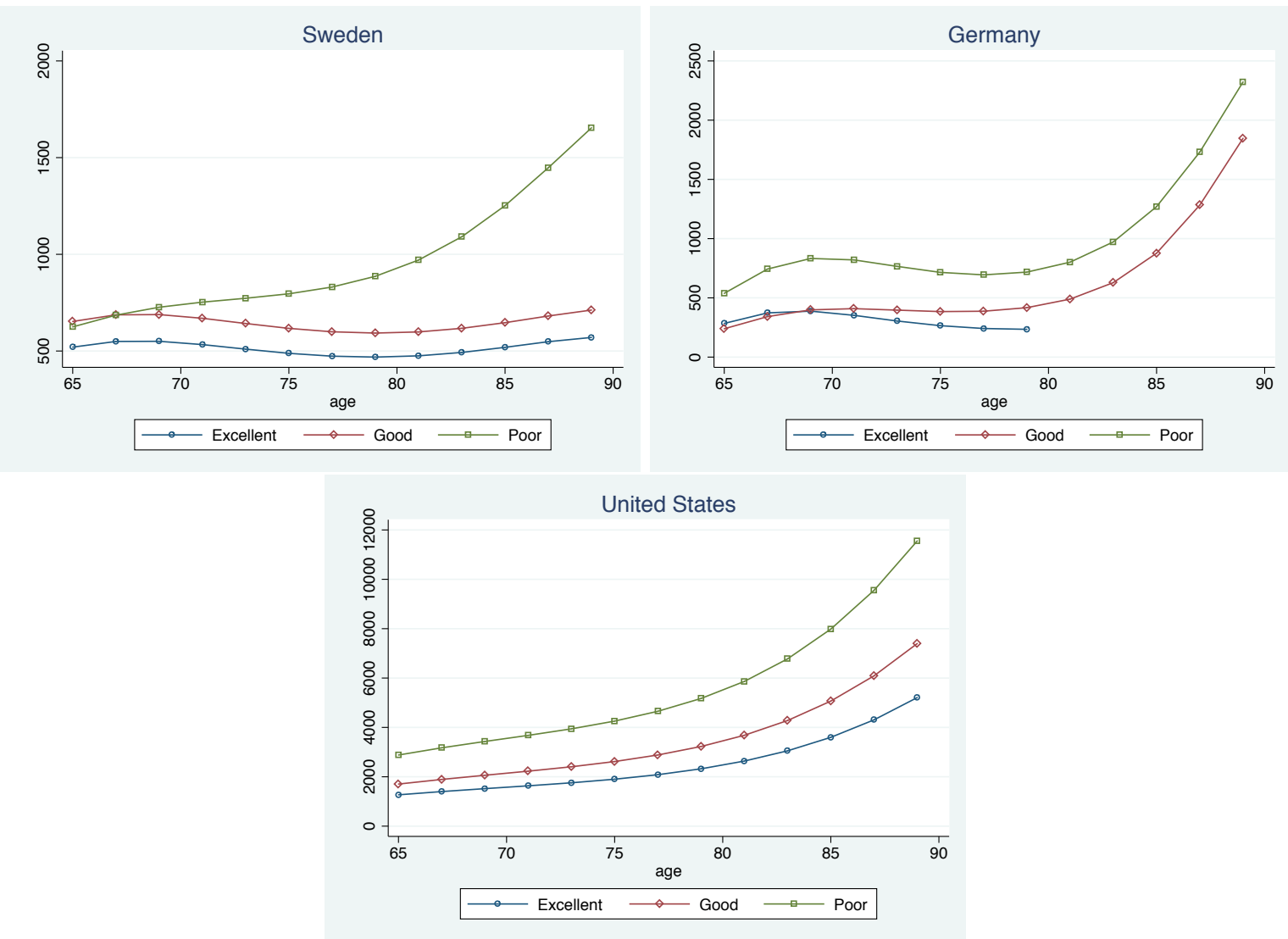

Figure 8: Expected Mean Medical Expenses by Health, Median-Income Singles

based on household size (single or couple), income, health status and age. Figure 8 shows expected mean medical and nusing home expenses for a single person of median income by health status, for three countries - one from each group in terms of long-term care coverage. As we would expect, in all three, people in worst health pay the most. However, the orders of magnitude of the expenses are markedly different at all ages. For exampe, at age 90, a person of median income in poor health might expect to spend about $\$ 12,500$ in the U.S. in OOP medical expenses. A similar person in Sweden would spend, on average, just over one-tenth that, and the expense level is $\$ 2,200$ in Germany. ${ }^{3}$ Notice that the magnitude rises as we progress from group (A) to (B) to (C), i.e. from Sweden to Germany to the U.S.

Figure 9 presents, for the same countries, mean expected medical expenses for singles of good health by income quintile. The figure demonstrates that correlation between income and medical expenses becomes stronger as the extent of privatization of coverage rises. In Sweden, with universal public coverage of

\footnotetext{
${ }^{3}$ We cannot reliably measure expenses for persons above age 90 in Europe because of small sample sizes, and this may raise concerns that we are underestimating expenses for the oldest old. While this is true, universal, or nearly, coverage of both health care and long-term care in these countries is a strong form of insurance and we rely on that information to assume that there is no hidden spike past age 90 . In our data, in fact, past age 90 we find a reduction in OOP medical expenses.
} 

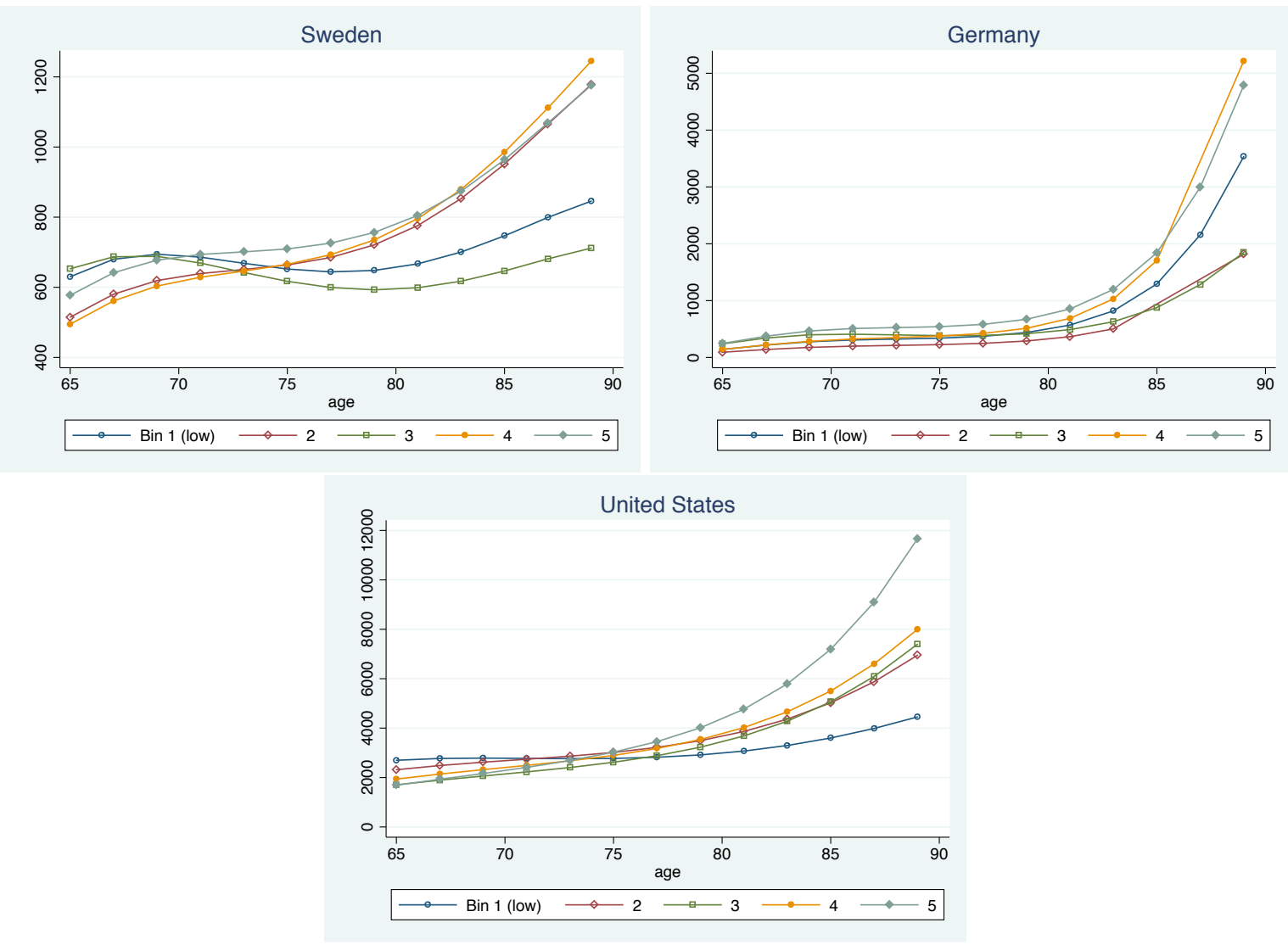

\section{Figure 9: Expected Mean Medical Expenses by Income, Good Health Singles}

both health care and long-term care, everyone pays roughly similar amounts out of pocket, regardless of income. Even at age 90 , the distribution ranges between $\$ 700$ and $\$ 1,200$, and is not monotone in income. In Germany, where there is more OOP spending on medical care and long-term care due to a degree of privatization in the system, the upper two quintiles spend most out of pocket. At age 90, the top two quintiles spend on average about $\$ 5,000$ on medical care, compared to about $\$ 2,000-\$ 3,000$ for the lower three quintiles. Finally, in the U.S. medical expenses are strongly monotonic in income, with the highest quintile at age 90 spending about $\$ 5,000$ more than the next quintile down, at about $\$ 15,000$, and that difference is exacerbated further later in life.

\subsection{Housing Markets}

There is wide variation in housing and mortgage markets across the countries in our sample, owing to differing regulations in the markets directly, and indirectly via tax policies, for example (ECB (2003)). There is variation in the extent of mortgage interest exemption, and in rental market policies, including public ownership of rental property (very high in the Netherlands, for example) and rent controls. There is significant variation in downpayment requirements at mortgage origination, ranging from minimum $40 \%$ 
in Germany to no regulated minimum in the Netherlands. These factors are likely to contribute to the variation in the rate of homeownership at age 65 , but as our interest is in what happens to home owners after age 65, we need to focus on differences in housing and mortgage markets targeting specifically the older population. Here, variation in availability of home equity release products for the elderly (such as reverse mortgages in the U.S.) may matter, and capital gains and estate taxation may play a role. We are still investigating these aspects of the countries in our sample, but for our first-pass exercise, we will not vary housing and mortgage markets across countries, in order to focus on the role of out-of-pocket expense risk. We will later relax these assumptions. Some details about housing markets for the countries in our sample are in Appendix A.3.

\section{Summary and Interpretation of Empirical Facts}

In sum, there are two distinct groups of countries in our sample: in one group, retirees spend down their wealth much more slowly than in the other group. We characterize the two groups by focusing on just two countries, U.S. and Sweden, and find that the significant difference in the rate of decumulation of net worth is driven mainly by retirees spending down their financial wealth, while homeownership profiles and median housing profiles are similar in the two countries and show similar rates of decumulation. In other words, saving in housing and in financial assets display different patterns, underscoring the need of treating them as distinct.

From institutional analysis, we find that Swedish retirees, unlike those in the U.S., have extensive public coverage of out-of-pocket medical and long-term-care expenses. In our data, we find that at age 90 Swedish retirees may spend, on average, about one-tenth of what U.S. retirees spend on medical and long-term care out of pocket.

Put differently, while in both countries homeownership patterns are similar, retirees in a low-risk environment spend down financial wealth more rapidly, while in a high-risk one, they hold on to their financial assets. This is consistent with the theory that financial assets are impacted by risk considerations, while housing assets are not. From this perspective, studying household wealth in retirement as just net worth conceals important differences in asset types and motivations for holding them: precautionary motives may be responsible for accumulation and spending patterns in financial wealth, while for housing assets, other explanations are needed, such as bequest motives, differences in housing markets and the mortgage markets, and the like.

In the remainder of the paper, we quantify the role of OOP spending risk on saving in retirement by testing to what extent the differences in risk characteristics in Sweden and the U.S. are responsible for differences in the rate of decumulation of financial assets and overall wealth. We also test the hypothesis that risk has a smaller impact on housing assets. In order to conduct the experiment, we propose a life- 
cycle model of saving in retirement, where households face a number of uninsurable idiosyncratic risks and can choose between homeownership and renting. We then calibrate the model to get at the answers to the central questions.

\section{$5 \quad$ Model}

The model is a modified version of the baseline model in Nakajima and Telyukova (2013). In the model as in the data, we focus on retired households, so that we can avoid dealing with the labor supply decision of the elderly. (For a study on this issue using SHARE, see Erosa et al. (2012)). Thus, a household in the model starts out at age 65. Model households live until maximum age 99, but face age- and health-dependent probability of death each period.

A retiree household starts out as a homeowner or a renter. In each period, the household chooses consumption and financial saving, and makes a decision regarding housing. For a homeowner, the housing decision is whether to move out of the house or to stay in it. Homeownership provides utility benefits, in addition to consumption services from the house; these capture factors such as attachment to one's house and neighborhood, the ability to modify one's house to individual taste, but also some financial benefits of ownership that are not explicitly in the model, such as tax exemption of imputed rents of owner-occupied housing, mortgage interest payment deduction, or insurance against rental rate fluctuation. In addition, homeowners are able to borrow against their home equity; the collateral constraint can change with age. See Nakajima and Telyukova (2012) for the motivation of this assumption.

For a renter, the housing choice is only the size of the rental property. We abstract from the decision of a homeowner to move to a different, most likely smaller, house, or the decision of a renter to buy a house. These abstractions are motivated by the observation in the data that the proportion of homeowners making downsizing moves is small, as is the proportion of renters who purchase a home late in life. Finally, renters are not able to borrow; this is motivated by the observation in our data that the median amount of unsecured debt among retirees is small, regardless of the country.

In addition to the mortality shocks, all households are subject to two other types of idiosyncratic shocks: a health status shock, which is conditioned on age and current health, and out-of-pocket medical expenditures, conditioned on age, health status and income.

Households get pension income, as well as interest income from their financial assets if any. Households also have access to a government-provided consumption floor, which captures social insurance programs for the impoverished elderly such as Medicaid in the U.S. Finally, households have a warm-glow bequest motive.

From the perspective of country comparison, the features of the model that can be changed to examine 
cross-country variation are health status shocks, medical expense shocks, details of the mortgage and housing markets, expressed via transaction costs and collateral constraints, and the consumption floor. We will also vary the initial type distribution of households to match each country's type distribution at age 65 in the data. We discuss this further in the Calibration section.

Formally, the state variables of a household are $(i, b, m, x, h, a)$ : its age, income, health status, medical expenses, amount of housing, and its financial assets. In order to save notation, we use $h=0$ to represent a renter. $h>0$ means that a household is a homeowner with a house size of $h$.

The simplest problem is the problem of the renter. We describe it in recursive form, using primes to denote the next period:

$$
\begin{aligned}
V(i, b, m, x, h=0, a)= & \max _{\tilde{h}, a^{\prime} \geq 0}\{u(c, \tilde{h}, i, 0) \\
& \left.+\beta \sum_{m^{\prime}>0, x^{\prime}} \pi_{i+1, m, m^{\prime}}^{m} \pi_{i+1, b, m^{\prime}, x^{\prime}}^{x} V\left(i+1, b, m^{\prime}, x^{\prime}, 0, a^{\prime}\right)+\beta \pi_{i+1, m, 0}^{m} v\left(a^{\prime}\right)\right\}
\end{aligned}
$$

subject to:

$$
\begin{aligned}
& \tilde{c}+a^{\prime}+r_{h} \tilde{h}+\psi_{i} x=(1+r) a+\psi_{i} b \\
& c= \begin{cases}\max \left\{\psi_{i} \underline{c}-r_{h} \tilde{h}, \tilde{c}\right\} & \text { if } a^{\prime}=0 \\
\tilde{c} & \text { otherwise }\end{cases}
\end{aligned}
$$

The renter chooses the level of financial assets to carry over to the next period $\left(a^{\prime}\right)$ and the property that he rents in the current period $(\tilde{h})$ to maximize the sum of three components. The first component is the period utility, which is a function of nonhousing and housing consumption, the tenure status of the renter, $o=0$, and average household size for age $i$. The second component is the discounted expected future value conditional on surviving to the next period $\left(m^{\prime}>0\right)$. Notice that $b$ does not change, and the renter remains a renter $\left(h^{\prime}=h=0\right)$. The expectation is formed based on the transition matrix $\pi^{m}$ of the health status shock, which depends on age $i+1$ and current health $m$, and $\pi^{x}$ of the medical expense shock, which depends on next period's age, income and health status. The third component of the maximand in the Bellman equation (1) is the utility from bequests, where $m^{\prime}=0$ indicates death. Notice that, for a renter, the only assets left as estate are financial assets $\left(a^{\prime}\right)$. Equation (2) is the budget constraint of the renter. The parameter $\psi_{i}$ multiplying income is a scaling parameter that allows us to account for data couple versus single households, and is age-specific to capture how the probability of being a couple changes with age. The term $\psi_{i} x$ captures the medical expense shock, adjusted for household size in an age-specific way. Equation (3) represents the lower bound of consumption guaranteed to the household through the social insurance program, which is also dependent on the household size. The consumption floor is available only 
when the renter chooses not to save anything $\left(a^{\prime}=0\right)$ and the cost of the rent is figured in as part of the benefit.

The recursive problem of a homeowner is a choice between staying in his current house $\left(V_{1}\right)$, or selling the house and becoming a renter $\left(V_{0}\right)$.

$$
V(i, b, m, x, h, a)=\max \left\{V_{0}(i, b, m, x, h, a), V_{1}(i, b, m, x, h, a)\right\}
$$

The problem of the owner who decides to sell and become a renter is:

$$
\begin{aligned}
V_{0}(i, b, m, x, h, a)=\max _{a^{\prime} \geq 0}\{ & u(c, h, i, 1) \\
& \left.+\beta \sum_{m^{\prime}>0, x^{\prime}} \pi_{i+1, m, m^{\prime}}^{m} \pi_{i+1, b, m^{\prime}, x^{\prime}}^{x} V\left(i+1, b, m^{\prime}, x^{\prime}, 0, a^{\prime}\right)+\beta \pi_{i+1, m, 0}^{m} v\left(a^{\prime}\right)\right\}
\end{aligned}
$$

subject to:

$$
\begin{aligned}
& \tilde{c}+a^{\prime}+\psi_{i} x+h(\kappa+\delta)=h+(1+\tilde{r}) a+\psi_{i} b \\
& \tilde{r}= \begin{cases}r & \text { if } a \geq 0 \\
r+\iota_{m} & \text { if } a<0\end{cases} \\
& c= \begin{cases}\max \left\{\psi_{i} \underline{c}, \tilde{c}\right\} & \text { if } a^{\prime}=0 \\
\tilde{c} & \text { otherwise }\end{cases}
\end{aligned}
$$

Relative to the renter problem above, first, the current tenure status is a homeowner $(o=1)$ with the house size of $h$, in the period utility function. Second, the budget constraint (6) does not include rent, but includes income from selling the house $h$, net of the current maintenance cost $(\delta)$ and the selling cost $(\kappa)$. Third, the interest rate is different depending on whether the homeowner is a net saver (in this case the interest rate is $r$ ), or a net borrower (the interest rate is $r+\iota_{m}$ ). Fourth, the household is eligible for the consumption floor if $a^{\prime}=0$. Also notice that the household begins the next period as a renter $\left(h^{\prime}=0\right)$.

The problem of the homeowner who decides to stay in his house is characterized by:

$$
\begin{aligned}
V_{1}(i, b, m, x, h, a)= & \max _{a^{\prime} \geq-h\left(1-\lambda_{i}\right)}\{u(c, h, 1) \\
& \left.+\beta \sum_{m^{\prime}>0, x} \pi_{i+1, m, m^{\prime}}^{m} \pi_{i+1, b, m^{\prime}, x^{\prime}}^{x} V\left(i+1, b, m^{\prime}, x^{\prime}, h, a^{\prime}\right)+\beta \pi_{i+1, m, 0}^{m} v\left(h+a^{\prime}\right)\right\}
\end{aligned}
$$

subject to (7) and:

$$
\tilde{c}+a^{\prime}+\psi_{i} x+h \delta=(1+\tilde{r}) a+\psi_{i} b
$$

First, a stayer homeowner can borrow against the house up to $1-\lambda_{i}$ percent of equity. Second, in the case of death, the estate is the consolidated asset position, which now includes the value of housing $(h)$. Third, the budget constraint includes the maintenance cost $(\delta h)$. 


\section{Calibration}

The goal of the computational experiment is to evaluate the extent to which differences in OOP medical and long-term care expense risk can account for similarities and differences in saving in retirement across countries. The differences in OOP expense risk are directly observable in our data, and the model will incorporate these direct measurements. Once again, we want to measure how much of the difference in the rate of decumulation of wealth by retirees in the U.S. and Sweden is accounted for by differences in risk in retirement. We also want to test that risk impacts housing and financial assets differently.

First, we calibrate our model to the U.S. data. Our calibration proceeds in two steps: in the first step, we calibrate the parameters that are directly observable in the data, while in the second, we estimate the remaining parameters to match the cross-sectional age profiles that we documented in the data for the U.S. Then, we keep the preference (second-stage) parameters fixed, and recalibrate desired observable parameters that describe the initial distribution and risk in Swedish data. For this changed calibration, we compute the optimal saving decisions of retirees, to see how closely the model can account for the differences between U.S. and Swedish data.

\subsection{First-Stage Calibration}

\subsubsection{Health Status and Mortality Risk}

In both the HRS and SHARE, households are asked to self-report their health status, and we group it into three categories: excellent (1), good/average (2) and poor (3). We also add death (0), so the transition matrix is defined accordingly. We estimate the transition probabilities by age and current health status. In the HRS, we take any pair of consecutive survey waves (1996-1998, 1998-2000, 2000-2002, etc.) and assuming stationarity, pool them all together to create two pooled consecutive waves. In SHARE, we only have two consecutive waves, and hence compute the probabilities based on 2004-2006 waves. Table 1 presents the resulting probabilities for the U.S. and Sweden, for four selected age groups, though we estimate separate probabilities for each model age (i.e. age 65, 67, 69, etc.)

The measured transition probabilities in Sweden are slightly noisier than in the U.S. because of much smaller sample sizes for older ages. Some resulting irregularities and nonmonotonicity aside (e.g. occasional zero probabilities for Sweden), the numbers in Sweden and the U.S. are comparable in magnitude, and have the logical tendency: probability of death increases in age and is higher the worse is the respondent's health. In addition, health deteriorates with age, and is less persistent with age, owing to a higher probability of death. We plan to confirm and make more robust the mortality numbers with another source from Swedish data, because in many sample attrition cases in SHARE, we cannot identify whether the former respondent is still alive or died; in such cases, we do not assume death. 
Table 1: Health Status Transition, Selected Age Groups (Percent)

\begin{tabular}{|c|c|c|c|c|c|c|c|c|c|}
\hline \multicolumn{10}{|c|}{ UNITED STATES } \\
\hline \multicolumn{5}{|l|}{ Age 65} & \multicolumn{5}{|l|}{ Age 75} \\
\hline & Dead & Excellent & Good & Poor & & Dead & Excellent & Good & Poor \\
\hline Excellent & 1.3 & 72.8 & 21.5 & 4.4 & Excellent & 3.9 & 60.1 & 26.9 & 9.2 \\
\hline Good & 2.2 & 25.8 & 53.3 & 18.7 & Good & 6.6 & 21.1 & 46.9 & 25.4 \\
\hline Poor & 9.6 & 6.1 & 20.7 & 63.7 & Poor & 16.3 & 3.8 & 17.6 & 62.3 \\
\hline \multicolumn{5}{|l|}{ Age 85} & \multicolumn{5}{|l|}{ Age 95} \\
\hline & Dead & Excellent & Good & Poor & & Dead & Excellent & Good & Poor \\
\hline Excellent & 10.5 & 46.8 & 27.1 & 15.6 & Excellent & 28.5 & 29.5 & 19.8 & 22.3 \\
\hline Good & 14.7 & 17.0 & 37.8 & 30.5 & Good & 32.9 & 12.9 & 26.8 & 27.5 \\
\hline Poor & 28.8 & 5.1 & 13.2 & 52.9 & Poor & 56.9 & 4.2 & 13.6 & 25.3 \\
\hline \multicolumn{10}{|c|}{ SWEDEN } \\
\hline \multicolumn{5}{|l|}{ Age 65} & \multicolumn{5}{|l|}{ Age 75} \\
\hline & Dead & Excellent & Good & Poor & & Dead & Excellent & Good & Poor \\
\hline Excellent & 0.4 & 67.6 & 23.7 & 8.3 & Excellent & 3.8 & 54.3 & 20.8 & 21.0 \\
\hline Good & 2.7 & 17.6 & 44.8 & 34.8 & Good & 0.8 & 16.4 & 40.0 & 42.8 \\
\hline Poor & 0.0 & 3.7 & 23.4 & 72.9 & Poor & 18.4 & 12.1 & 10.7 & 58.9 \\
\hline \multicolumn{5}{|l|}{ Age 85} & \multicolumn{5}{|c|}{ Age 89-93 } \\
\hline & Dead & Excellent & Good & Poor & & Dead & Excellent & Good & Poor \\
\hline Excellent & 8.2 & 45.2 & 22.3 & 24.3 & Excellent & 25.5 & 32.7 & 24.5 & 17.4 \\
\hline Good & 6.1 & 5.2 & 42.6 & 46.2 & Good & 16.8 & 11.8 & 33.5 & 38.0 \\
\hline Poor & 20.2 & 0.0 & 17.0 & 62.8 & Poor & 13.9 & 0.0 & 7.4 & 78.8 \\
\hline
\end{tabular}

${ }^{1}$ Sources: HRS 1996-2006, SHARE 2004-2006.

\subsubsection{Medical Expenses}

We estimate the distribution of log-OOP medical expenditures by age, health, income quintile and household size (single or couple).The mean, standard deviation and probability of zero expenses are estimated as quartics in age, and include interaction terms between age and the other three variables. Under the assumption of log-normality of medical expenses, we then compute the expected mean and standard deviation of level medical expenses. Figure 10 reproduces, once again, mean medical expenses for the U.S. and Sweden, for single households in the middle income bin by health. As we would expect, people in worse 

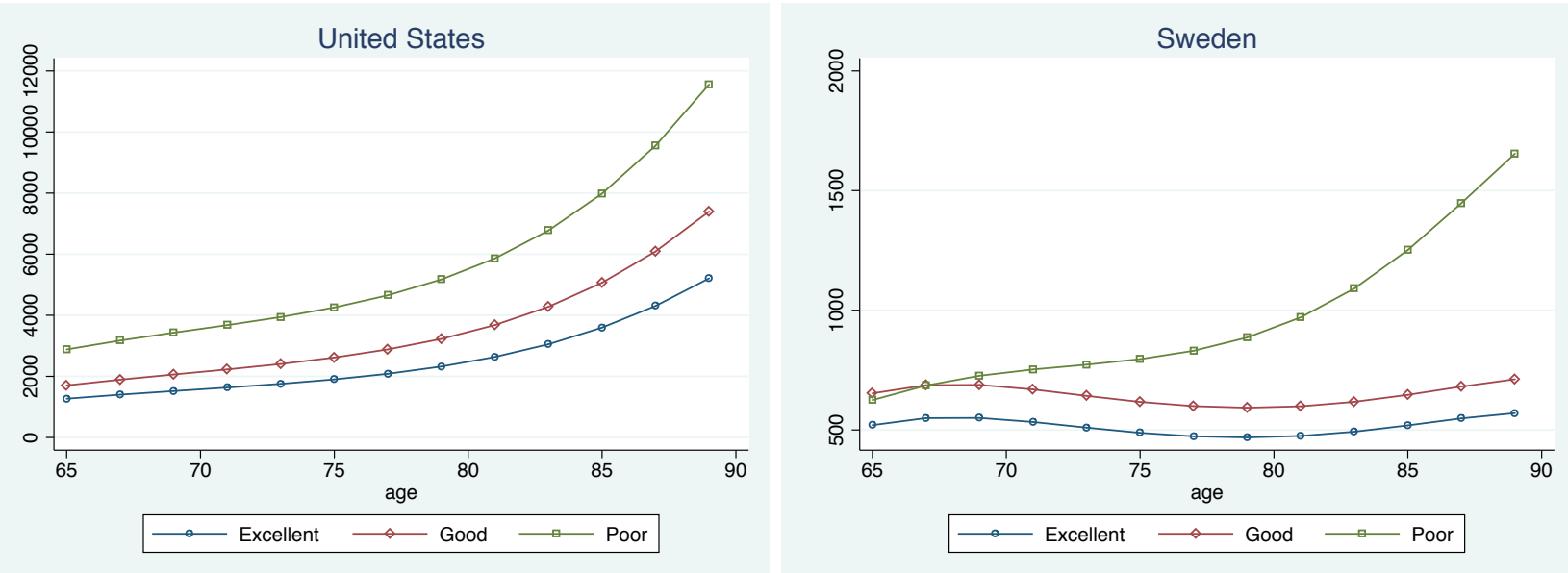

Figure 10: Expected Mean of OOP medical expenditures, mid-income singles, by health

health pay higher expenses, but in Sweden, the differences in expenses by health are small compared to the U.S., and the level of expenses is an order of magnitude lower.

\subsubsection{Initial Distribution at Age 65}

As another input into the model, we construct the initial distribution of households across all the state variables at age 65 . The dimensions of the distribution are thus income quintile, health status, homeownership status and amount of housing for homeowners, and the financial asset position. We treat income as fixed with age, as it incorporates pension and social security income and does not vary with the life cycle of a given cohort in our data. ${ }^{4}$ Tables 2 and 3 summarize the dimensions of the initial distribution not already discussed. The distribution of health states is similar in the U.S. and Sweden, although more respondents classify themselves in excellent health in the U.S. than in Sweden. As already discussed, the home ownership rate is higher in the U.S. than in Sweden at age 65, and somewhat more retirees are net borrowers in Sweden at age 65. The after-tax income distribution displays more dispersion in the U.S. compared to Sweden.

\subsubsection{Remaining First-Stage Parameters: Housing Costs}

Table 4 shows the calibration for housing cost parameters that we use. We take these numbers directly from the data or the literature for the U.S.. The saving interest rate is $4 \%$ per year, since the financial asset in the model captures all of the financial assets that retirees hold. The mortgage interest premium is $1.6 \%$ above that rate, that is, the mortgage interest rate is $5.6 \%$. The maintenance cost of a house is $1.7 \%$ per year of the house's value. The selling cost of a house is $6.6 \%$ of the house's value, and captures

\footnotetext{
${ }^{4}$ We normalize income by household size to take into account that couples' income is larger than singles' income by a factor of 1.4 , on average.
} 
Table 2: Initial Distribution at Age 65

\begin{tabular}{lcc}
\hline & U.S. & Sweden \\
\hline Health status & & \\
1 (excellent) & 0.46 & 0.38 \\
2 (good) & 0.32 & 0.33 \\
3 (poor) & 0.22 & 0.29 \\
\hline Tenure & & \\
Homeowner & 0.88 & 0.82 \\
Renter & 0.12 & 0.18 \\
\hline Net financial asset position & & \\
Saver & 0.79 & 0.73 \\
Borrower & 0.21 & 0.27 \\
\hline
\end{tabular}

Table 3: Initial Distribution at 65 - Income Bins

\begin{tabular}{l|rrrrr}
\hline & 1 & 2 & 3 & 4 & 5 \\
\hline U.S. & 8,028 & 14,517 & 21,330 & 30,273 & 48,920 \\
Sweden & 8,228 & 11,240 & 13,370 & 17,425 & 27,947 \\
\hline
\end{tabular}

After-tax income. 2000 PPP-adj. U.S. dollars.

Table 4: First-Stage Housing Cost Parameters, U.S.

\begin{tabular}{lll}
\hline Parameter & Description & Value \\
\hline$\delta$ & Maintenance cost of housing $^{1}$ & 0.017 \\
$\kappa$ & House selling cost & 0.066 \\
$r$ & Saving interest rate $^{1}$ & 0.040 \\
$\xi$ & Mortgage interest premium $^{1}$ & 0.016 \\
\hline
\end{tabular}

${ }^{1}$ Annualized value.

all the financial and time costs associated with the process of selling a house. See Nakajima and Telyukova (2012) for justification of these parameter choices.

For the experiment we will assume these parameters to be the same in Sweden, in order to hold the influence of housing market differences on saving choices constant. 


\subsection{Second-Stage Calibration: United States}

We estimate the remaining parameters for the baseline model to the U.S. data. The parameters include preference parameters and some others; the estimation matches U.S. cross-sectional age profiles that we described in the Data section to the ones derived from the model.

With respect to preferences, households discount the next period using the factor $\beta$. We use the following period utility function with constant relative risk aversion:

$$
u(c, h, i, o)=\frac{\chi_{i}\left(c^{\eta}\left(\omega_{o} h\right)^{1-\eta}\right)^{1-\sigma}}{1-\sigma}
$$

$\eta$ is the Cobb-Douglas aggregation parameter between non-housing consumption goods $(c)$ and housing services $(h) . \sigma$ is the risk aversion parameter. $\omega_{o}$ represents the extra utility of housing. For renters $(o=0)$, $\omega_{0}$ is normalized to unity. For homeowners $(o=1), \omega_{1}>1$ represents benefits of homeownership, both financial that we do not explicitly model, and nonfinancial. $\chi_{i}$ is the adjustment for household size, which takes into account the household equivalence scale in consumption and aggregation of utility according to the age-specific probability that the household is a couple. ${ }^{5}$

A household gains utility from leaving bequests. When a household dies with the consolidated wealth of $a$, the household's utility function takes the form:

$$
v(a)=\gamma \frac{(a+\zeta)^{1-\sigma}}{1-\sigma}
$$

Here, $\gamma$ captures the strength of the bequest motive, and $\zeta$ affects the marginal utility of bequests.

In the second stage of the estimation, we estimate the parameters to maximize the fit of the model according to the cross-sectional age profiles of median net worth, housing and financial wealth, homeownership rate and the net debt rate, i.e. the percent of each age group with negative financial assets net of equity debt. The estimation procedure minimizes the (squared, weighted) distance between these age profiles in the model and the data. Table 5 presents the parameters estimated in the second stage.

The coefficient of risk aversion $\sigma$ is on the lower end of the standard range in the macro literature, at 1.5, which means that high curvature of the utility function is not the driving force behind our results on the quantitative role of spending risk below. The estimates imply that living in an owned home gives retirees 2.85 times the utility benefit of being a renter. As we mentioned before, this parameter captures both utility benefits, such as attachment to the house, the neighborhood, the custom features of the house, as well as financial benefits, such as insurance against rental rate fluctuation or tax exemption of mortgage interest, which we do not model explicitly. The consumption floor per adult is estimated at $\$ 11,351$ per

\footnotetext{
${ }^{5}$ Specifically, $\chi_{i}=\mathbb{P}_{i}(s=1) \times 1+\mathbb{P}_{i}(s=2) \times(1 / 1.34)^{1-\sigma}$, where $\mathbb{P}_{i}(s=n)$ is age-specific probability of household size being $n$, and 1.34 is the household equivalence scale for couples.
} 


\section{Table 5: Second-Stage Estimated Parameters, U.S. Benchmark}

\begin{tabular}{llr}
\hline Parameter & Description & Value \\
\hline$\beta$ & Discount factor $^{1}$ & 0.98 \\
$\eta$ & Consumption aggregator & 0.79 \\
$\sigma$ & Coefficient of RRA $^{2}$ & 1.50 \\
$\omega_{1}$ & Utility from ownership & 2.85 \\
$\gamma$ & Strength of bequest motive & 0.43 \\
$\zeta$ & Curvature of utility from bequests & 19626 \\
$\underline{c}$ & Consumption floor per adult ${ }^{1}$ & 11351 \\
$\lambda_{65}$ & Collateral constraint for age-65 & 0.43 \\
$\lambda_{73}$ & Collateral constraint for age-73 & 0.76 \\
$\lambda_{81}$ & Collateral constraint for age-81 & 0.99 \\
$\lambda_{89}$ & Collateral constraint for age-89 & 1.00 \\
$\lambda_{99}$ & Collateral constraint for age-99 & 1.00 \\
\hline \multirow{2}{*}{ Biennial value. }
\end{tabular}

adult per two years. This is in line with the non-Social-Security social insurance benefit computed by Hubbard et al. (1994), adjusted for inflation. Finally, we estimate the strength of the bequest motive at 0.43 , and the curvature parameter at $\$ 19,626$ - this parameter affects the threshold of wealth at which retirees find it valuable to leave a bequest.

The age-specific borrowing constraint $\lambda_{i}$ is estimated by piecewise-linear approximation, with the intervals of 8 years, and bounded between 0 and 1 . Thus, the borrowing constraint of a 67 -year-old is not the same as that of a 65-year-old. This parameter is pinned down by the percentage of retirees who are in debt, which is one of our estimation targets. The parameters imply that retirees at age 65 are able to borrow up to $57 \%$ of their home equity), but as they age, they become increasingly constrained, so that by age 81 , they can essentially no longer borrow. This is a parsimonious way to capture the fact that in the data borrowing becomes very costly for the elderly. Some, possibly a lot, of this cost comes from the supply side: elderly borrowers do not have easy access to traditional equity borrowing instruments because they fail the inherent income requirement for mortgage repayment (Caplin (2002)). The market that exists for reverse mortgages - instruments targeted at elderly borrowers - appears thin, which is both demandand supply-side driven (Nakajima and Telyukova (2013)). Here, we capture all these factors in reduced form via $\lambda_{i}$.

To assess the fit of the model with these parameters, figure 11 shows the age profiles in the U.S. data and in the model of median net worth, homeownership rate, median housing assets conditional on 


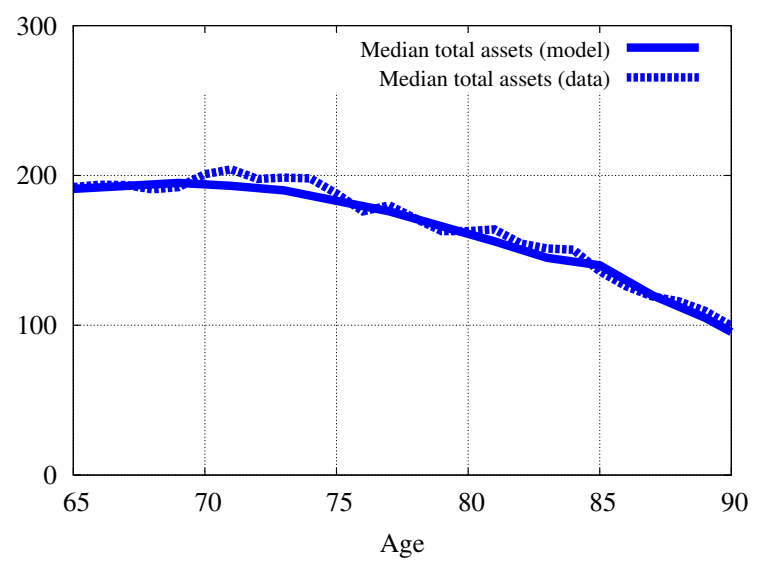

(a) Median Net Worth

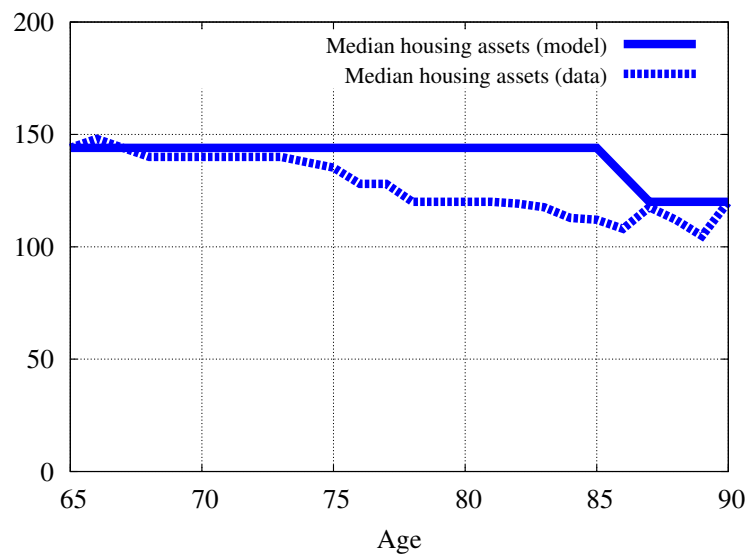

(c) Median Conditional Housing Assets

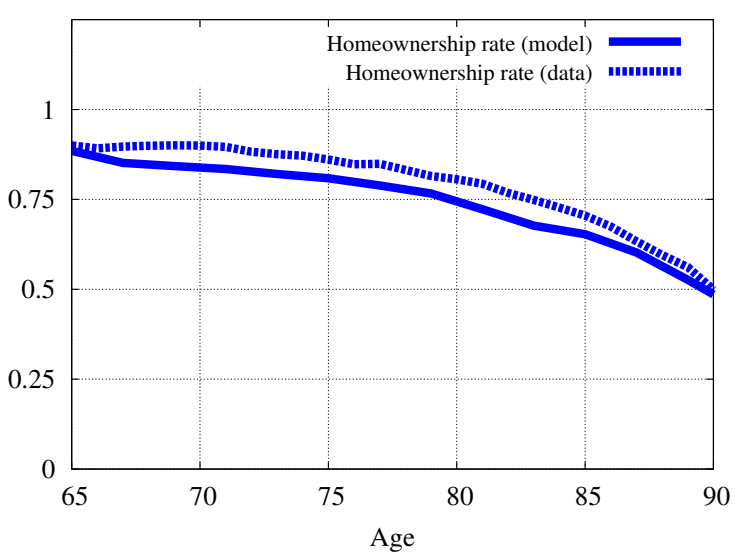

(b) Homeownership Rate

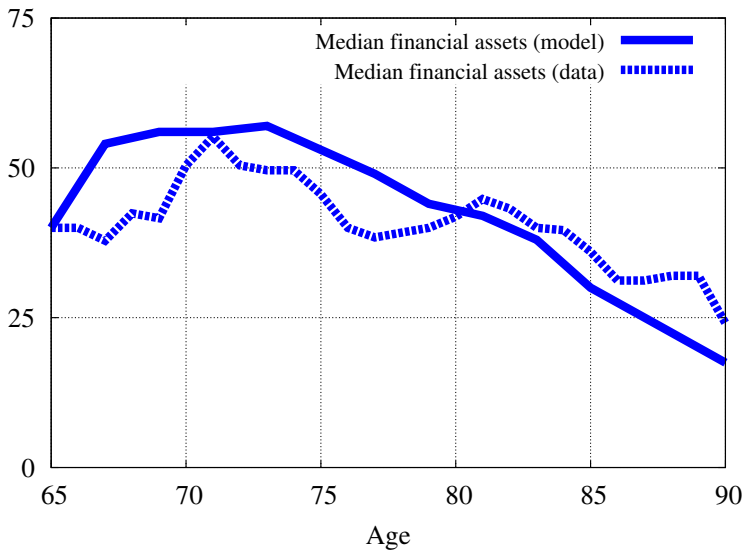

(d) Median Financial Assets

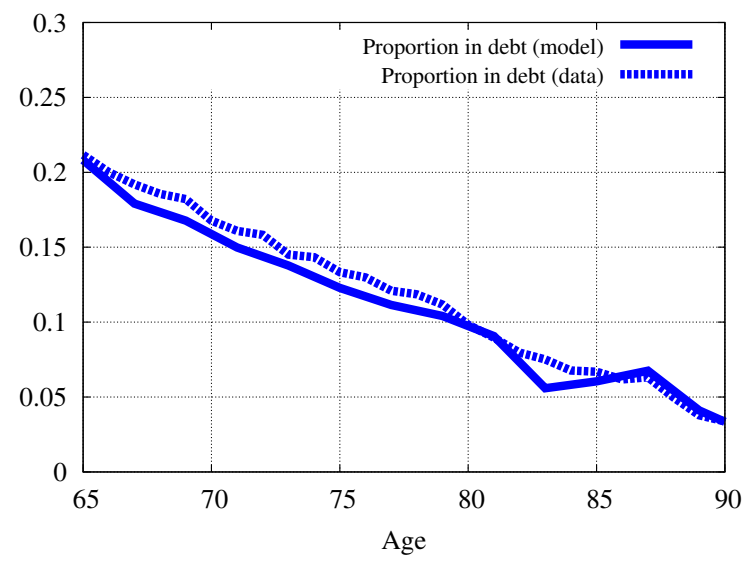

(e) Proportion in Net Debt

Figure 11: Benchmark Model Fit - Age Profiles in Model vs. U.S. Data 
ownership, median financial assets net of equity debt, and proportion of retirees in debt. The model replicates median total assets perfectly, and the homeownership rate very closely, at every age. The match of the remaining age profiles is also very good, though the model overstates the flatness of the median housing profile somewhat. This happens because in the model, there are only 11 house values possible, due to discretization, while in the data, home values are a continuous variable. Sensitivity analysis of the estimated parameters is currently in progress.

\section{Experiment: Effect of OOP Expense Risk on Saving in Retirement}

In this experiment, we use the preference parameters that we estimated in the model for the U.S., and under the assumption of preferences being identical in Sweden, as well as housing and mortgage markets being identical, change only the observable inputs for health status shocks, medical and nursing home expense shocks, and the initial distribution, as described in section 6.1.

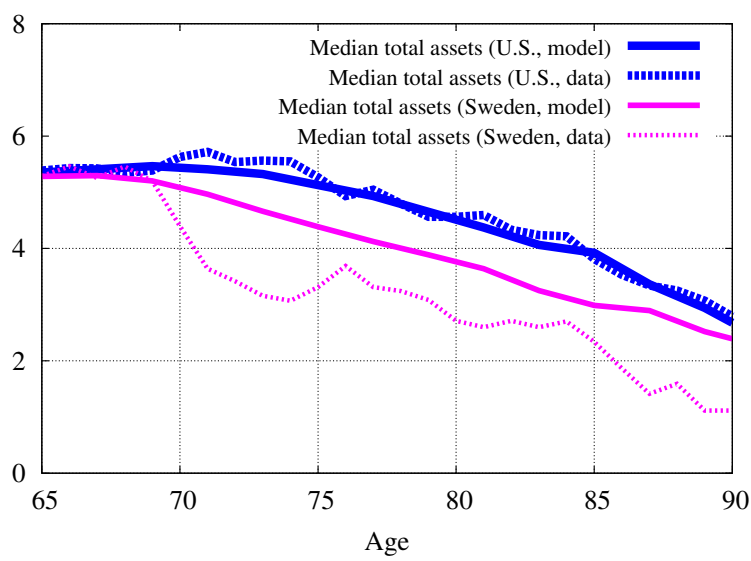

(a) Median Net Worth

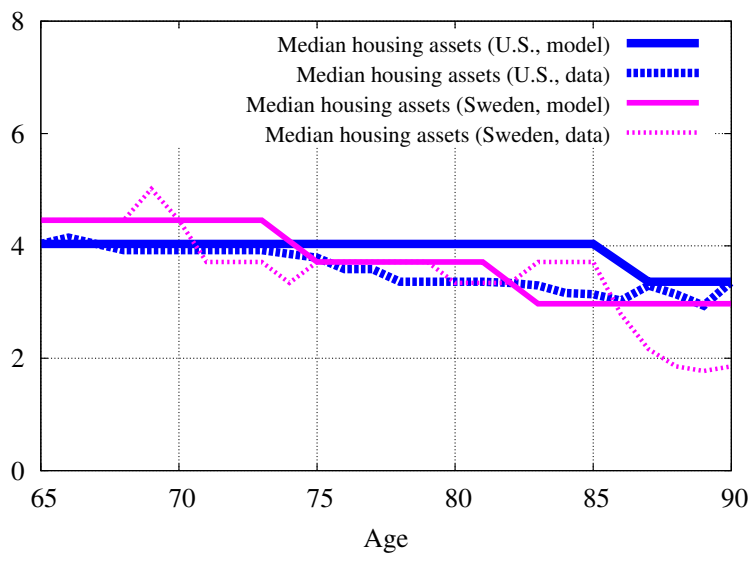

(c) Median Conditional Housing Assets

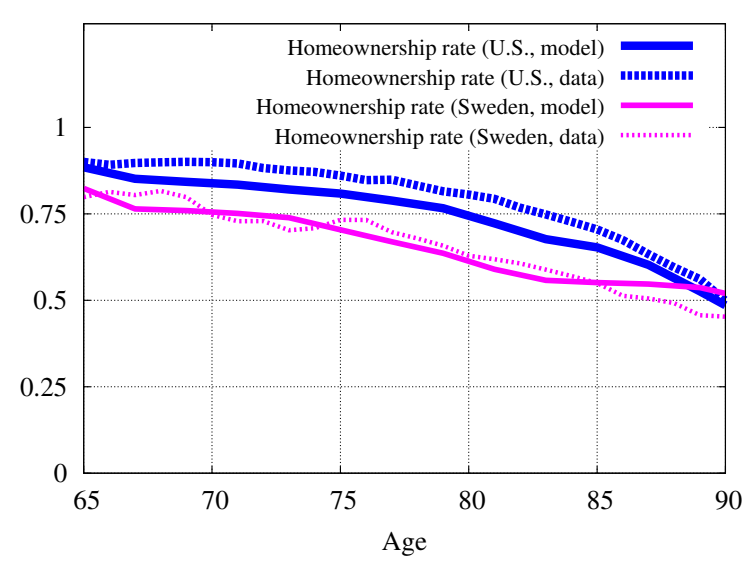

(b) Homeownership Rate

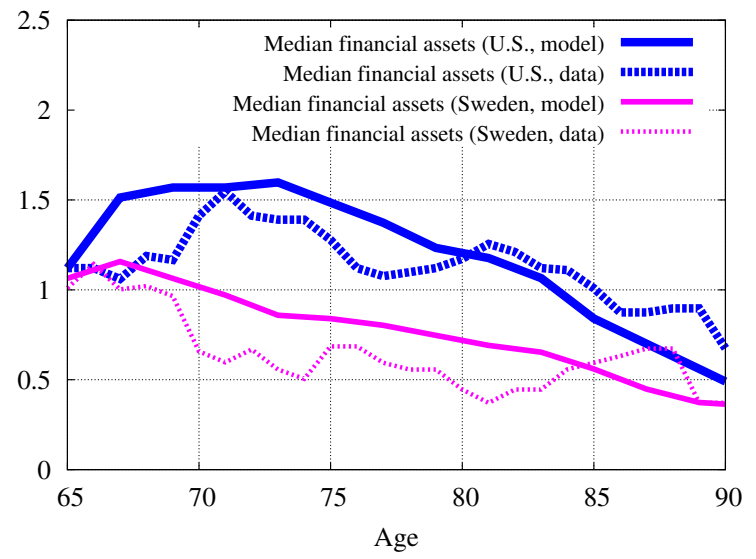

(d) Median Financial Assets

Figure 12: Role of OOP Expense Risk - U.S. vs Sweden, Model and Data 
Table 6: Role of OOP Expense Risk - U.S. vs Sweden

\begin{tabular}{l|rrr|rrr}
\hline & \multicolumn{3}{|c|}{ Median Net Worth } & \multicolumn{3}{c}{ Median Financial Assets } \\
\hline Age & \% difference & \% difference & model/ & \% difference & \% difference & model/ \\
& data & model & data $(\%)$ & data & model & data (\%) \\
\hline 67 & -1.4 & -0.8 & 56 & 4.9 & -19.4 & -395 \\
69 & -1.7 & -3.5 & 206 & -8.1 & -28.6 & 353 \\
71 & -35.2 & -7.0 & 20 & -57.2 & -34.8 & 61 \\
73 & -42.2 & -11.3 & 27 & -55.5 & -43.4 & 78 \\
75 & -35.9 & -13.3 & 37 & -40.5 & -40.4 & 100 \\
77 & -33.1 & -15.3 & 46 & -38.7 & -38.4 & 99 \\
79 & -31.2 & -15.4 & 49 & -44.9 & -56.2 & 81 \\
81 & -42.4 & -15.6 & 37 & -67.2 & -38.2 & 57 \\
83 & -37.5 & -18.9 & 50 & -55.9 & -35.4 & 63 \\
85 & -37.5 & -22.8 & 61 & -34.6 & -29.8 & 86 \\
87 & -56.9 & -12.8 & 23 & -14.5 & -32.6 & 225 \\
89 & -63.1 & -13.2 & 21 & -54.0 & -29.8 & 55 \\
91 & -64.9 & -4.7 & 7 & -51.1 & -11.1 & 22 \\
\hline Average & & & 49 & & & 68 \\
\hline
\end{tabular}

Figure 12 presents the predictions of the experiment. Looking at median net worth, the model generates about one-half of the difference between U.S. and Sweden as a result of the changed risk characteristics, on average. Note that, judging by the net worth differences, risk plays a diminishing role with age, because the ability of the model to account for the difference diminishes with age. This result echoes our findings in Nakajima and Telyukova (2012). The model correctly predicts that most of the difference is in the financial assets, and generates close to the overall difference in financial wealth between the two countries. The model is able to replicate, for example, that Swedish retirees dissave financial wealth faster than those in the U.S. The model also suggests that median housing assets and homeownership rates are not much impacted by risk, in that the age profiles of both variables look very similar, once differences in initial conditions are accounted for. However, the model overpredicts slightly the homeownership rate for Sweden late in life. That is, dissaving in housing assets late in life is not related to risk, according to our model, but is motivated by other factors, explicitly held constant in this experiment.

To quantify the results in figure 12, in table 6 we compute the difference in percent decline relative to age 65 for U.S. and Sweden in median net worth (columns 1,2) and financial assets (columns 4,5) in the 
data and the model. To be clear, for age group $j$ we compute, e.g. for net worth (nw):

$$
\operatorname{diff}_{j}^{n w}=100 *\left(\frac{\frac{\mathrm{nw}_{j}^{S E}}{n w_{65}^{S E}}-\frac{\mathrm{nw}_{j}^{U S}}{\mathrm{nw}_{65}^{U S}}}{\frac{\mathrm{nw}_{j}^{U S}}{\mathrm{nw}_{65}^{U S}}}\right)
$$

Columns 3 and 6 compute the ratio of model's predicted decline to that in the data: these numbers show how much of the differences in saving outcomes between U.S. and Sweden are accounted for by differences in out-of-pocket expense risk. The numbers differ by age, but simple averages of the numbers, as one possible summary, state that OOP spending risk accounts for $49 \%$ on average across ages of the difference between the U.S. and Swedish median net worth profiles. The number differs by age, on one occasion overpredicting the difference, but the "standard" range, excluding the outliers, is between 20 and $56 \%$, and even without outliers, the average is very stable at around one-half.

The model accounts, on average, for $68 \%$ of the difference between the financial assets of the two countries, but this average is much more sensitive, because there is more variation by age. The model sometimes overpredicts the difference, and on one occasion, predicts a change of the opposite sign from data. This results in a large range, but excluding the three outliers, the "standard" range is between 22 and $100 \%$.

To summarize, the model predicts that out-of-pocket medical and long-term-care spending risk affects primarily financial assets, and not housing assets, and accounts for about one-half of the difference in net worth between the two countries. There is indication that the role of risk diminishes with age, as the percent contribution of the model diminishes for older ages, but there is some non-monotonicity in the effect. This may suggest that risk has a larger impact on saving earlier in retirement, while later in life, other motives, such as bequest considerations or illiquidity of housing, are more important for continued positive wealth. We are investigating these other factors in ongoing work, subject to our ability to find good measurements for them.

\section{Conclusion}

We use harmonized cross-country data on twelve developed economies to document the patterns of (dis)saving among retirees in housing versus non-housing assets, and the extent of the retirement saving puzzle in these countries. We find that countries in our sample vary noticeably in the extent of the puzzle: one group of countries looks like the U.S., while in another group, retirees spend down their wealth much more rapidly. Focusing on the cases of U.S. and Sweden, countries with very different degrees of public insurance of healthcare and long-term care, we show that the differences in patterns of wealth decumulation come mainly from financial assets, suggesting that differences in risk in retirement affect mainly liquid saving, while housing assets are affected by other motivations. 
Our quantitative experiment, using a calibrated life-cycle model of saving in retirement, tests this theory by quantifying the extent to which differing risk characteristics in the two countries can account for the resulting differences in saving patterns. The model predicts that out-of-pocket spending risk accounts for one-half of the difference in median net worth decumulation between the U.S. and Sweden, and most of the difference in financial assets. The model predicts that risk affects primarily financial assets, and not housing assets; the differences in housing asset profiles and ownership of homes late in life must be due to other factors, which our experiment explicitly holds constant at this point.

There is a large variety of institutional differences between the U.S. and Sweden in addition to the differences in healthcare and long-term care insurance policies, concerning pension programs, social safety nets such as Medicaid in the U.S., housing markets, mortgage markets and the like. It is also possible that these institutional differences produce differences in preferences, such as bequest motives. In this paper, our goal was to document overall empirical facts on saving in retirement across countries, particularly as it pertains to housing and financial assets, and then to focus on the role of risk of high expenses late in life in accounting for these facts. We abstracted from testing the influence of other institutions because they are more difficult to measure in survey data. However, the role of these institutions is important to continue investigating. We leave these topics to ongoing and future research. 


\section{References}

Allin, Sara, Vaida Bankauskaite, Hans Dubois, Josep Figueras, Christina Golna, Susanne Grosse-Trebbe, Nadia Jemiai, David McDaid, Annette Riesberg, Jonas Schreyoegg, and Sarah Thomson, Snapshots of health systems, World Health Organization on behalf of European Observatory on Health Systems and Policies, 2005.

Ameriks, John, Andrew Caplin, Steven Paufer, and Stijn van Nieuwerburgh, "The Joy of Giving or Assisted Living? Using Strategic Surveys to Separate Public Care Aversion from Bequest Motives.," Journal of Finance, 2011, 66 (2), 519-561.

Angelini, Viola, Agar Brugiavini, and Guglielmo Weber, "The Dynamics of Homeownership among the 50+ in Europe," 2011. Mimeo.

Brown, Jeffrey R. and Amy Finkelstein, "Insuring Long-Term Care in the United States," Journal of Economic Perspectives, 2011, 25 (4), 119-142.

Caplin, Andrew, "Turning Assets into Cash: Problems and Prospects in the Reverse Mortgage Market," in Olivia S. Mitchell, Zvi Bodie, Brett Hammond, and Steve Zeldes, eds., Innovations in Retirement Financing, Philadelphia, PA: University of Pennsylvania Press, 2002, chapter 3, pp. 234-253.

Christelis, Dimitris, Dimitris Georgarakos, and Michael Haliassos, "Differences in Portfolios Across Countries: Economic Environment versus Household Characteristics," Review of Economics and Statistics, forthcoming.

De Nardi, Mariacristina, Eric French, and John Bailey Jones, "Why Do the Elderly Save? The Role of Medical Expenses," Journal of Political Economy, 2010, 118 (1), 39-75.

_, _, _, and Angshuman Gooptu, "Medicaid and the Elderly," 2012. Federal Reserve Bank of Chicago Economic Perspectives.

ECB, Structural Factors in the EU Housing Markets, Frankfurt: European Central Bank, 2003.

Erosa, Andres, Luisa Fuster, and Gueorgui Kambourov, "Labor Supply and Government Programs: A Cross-Country Analysis," Journal of Monetary Economics, 2012, 59 (1), 84-107.

Hubbard, R. Glenn, Jonathan Skinner, and Stephen P. Zeldes, "The Importance of Precautionary Motives in Explaining Individual and Aggregate Saving," Carnegie-Rochester Conference Series on Public Policy, 1994, pp. 59-125. 
_, _, and _ , "Precautionary Saving and Social Insurance," Journal of Political Economy, 1995, 103 (3), 360-399.

Hurd, Michael D., "Mortality Risk and Bequests," Econometrica, 1989, 57 (4), 779-813.

Lockwood, Lee M., "Bequest Motives and the Annuity Puzzle," Review of Economic Dynamics, 2012, $15(2), 226-243$.

Nakajima, Makoto and Irina A. Telyukova, "Home Equity in Retirement," 2012. Mimeo, UCSD.

_ and _ , "Reverse Mortgage Loans: A Quantitative Analysis," 2013. Mimeo, UCSD.

OECD, Long-term Care for Older People, OECD Publishing, 2005.

Venti, Steven F. and David A. Wise, "Aging and Housing Equity: Another Look," in David A. Wise, ed., Perspectives on the Economics of Aging, Chicago: University of Chicago Press, 2004, chapter 3, pp. $127-175$. 


\section{APPENDIX}

\section{A Institutional Details}

\section{A.1 Health Care}

This information is based on Allin et al. (2005).

Austria: statutory health insurance (SHI) - covers $95 \%$ of population mandatorily, $2 \%$ voluntarily. $19 \%$ of total expenditure was financed from user charges or direct payments (2000). Contributions represent from equal shares from employees and employers, accounting for $7.4 \%$ of salary in 2004 . There are ceilings for max income and contributions.

Belgium: $99 \%$ of population are covered by compulsory health insurance; reimbursements are differentiated by social-risk status, and thus, patients finance about $19 \%$ of health expenditure mostly through OOP payments (as well as some voluntary health insurance (VHI) premiums). OOP payments are capped based on family income and "other socioeconomic factors".

Denmark: tax-based universal system. Private payments cover about $17 \%$ of costs, via OOP co-pays for PT, dental, glasses and drugs, as well as contributions to voluntary health insurance schemes. (About $30 \%$ of population purchases VHI coverage for the co-pays.)

France: covers via national social insurance system by tax-based financing and complementary VHI. OOP payments cover $9.8 \%$ of total expenditure, VHI premia $-13.2 \%$.

Germany: universal healthcare coverage; OOP expenses only for drugs (copays). Starting in 2004, co-pays introduced for outpatient visit and have been raised for other benefits.

Greece - one of the most "privatized" in the EU; voluntary payments by individuals or employers represent $42 \%$ of total health expenditure (2002). There are both compulsory HI and VHI schemes, the latter purchased by $8 \%$ of population.

Italy - universal healthcare; OOP payments capped at EUR36 since 2002 for outpatient care; co-pays for drugs and specialist services are low and make a low contribution to overall cost (2.9\% in 2002). There are also private healthcare services and OTC drugs that require OOP payment; $15 \%$ has complementary private health insurance either individually or through employer.

Netherlands -(a) national insurance scheme for exceptional/ high-cost medical expenses; (b) compulsory sickness funds for those with income below EUR 30000, with PHI for those above the ceiling (28\% of population). (c) Supplementary private insurance covers dentists and the like. PHI and OOP payments cover, respectively, $16 \%$ and $5 \%$ of total medical costs.

Spain - universal public care, plus $15 \%$ of population purchase also private insurance (to avoid lines). 
Sweden - compulsory tax-based system for the entire population; voluntary additional insurance is very limited. Private expenses are OOP and premia (14\% of total); $90 \%$ of employers pay for voluntary insurance to avoid paying for sick leave.

UK - NHI renders OOP medical expenses at zero; uptake of private medical insurance is low $(11.5 \%$ of population). Service is usually free at point of service.

\section{A.2 Long-Term Care}

Based on the information in OECD (2005), we categorize the countries as follows:

(A) All public long-term care, no means-testing, no OOP expenses: Sweden, Netherlands, Denmark, Norway (not in our sample). Eligibility does not depend on assets.

(B) A mix, some OOP expenses: Austria, Germany. Low or no dependence on assets.

(C) A lot of OOP expenses/means-testing: Spain, Switzerland (not in sample), Italy, UK, U.S.. Eligibility depends on assets.

Group A: Netherlands provides both home-care (consumer-directed budged) and institutional (in-kind) care benefits, which are universal (not means-tested). On the consumer's part, income-related co-payments are required. Usage: $2.4 \%$ of those aged $65+$ received long-term institutional care; $12.3 \%$ received home care benefits (2000).

Sweden similarly provides universal public long-term care in-kind benefits for both home and institutional care; users pay moderate amount of fees set by the local government. Usage: $7.9 \%$ institutional / $9.1 \%$ home care (2000).

Norway (not in our sample): also universal benefits for both home and institutional care; residents in institutions are charged about $80 \%$ of their income. Usage: $6 \%$ institutional / $18 \%$ home care (2000).

Group B: Austria provides a long-term care cash allowance universally (not means-tested), financed by general taxation, but the user will pay the difference between the benefit and actual cost, both for institutional care and home care. Usage: $3.6 \%$ of $65+$ received institutional long-term care; $14.8 \%$ received home care benefits. (2000)

Germany has social long-term care insurance for both home and institutional care, which is universal (not means-tested). Benefits are in-kind for nursing home care, and cash and in-kind for home care. For home care, the average OOP to cover additional/more expensive services were about EUR 130 per month on average (2003) - I do not know if this is a conditional number. For nursing home care, board/lodging are not covered (EUR 560 per month on average). Service charges in excess of statutory limit are EUR 313 per 
month on avg, though these can be covered by means-tested social assistance. Usage: 3.9\% institutional / $7.1 \%$ home care (2003).

Group C: Spain: in 1998, 73\% of total long-term care cost was met privately. There are social-care programs for both home and nursing home care, but they are all means-tested. In Spain, high prevalence of informal/family arrangements is noted. This is also true for Italy, where informal arrangements involving hiring of live-in help for care of the elderly are common.

Switzerland: private cost-sharing is "high" - no numbers provided. Benefits are in-kind and cash. Institutional care benefits are means-tested. Usage: 7\% institutional / 5.4\% home care (2000).

The U.K. has a tiered system. The NHS provides universal in-kind home-care and nursing home benefits, which is completely free. Social services provide additional such benefits, but they are meanstested, and users are charged according to ability to pay. Social Security provides cash home-care benefit in addition, which is means-tested. . Usage: 5.1\% institutional / 20.3\% home care (2000/2002).

In the U.S., Medicare and Medicaid both provide in-kind homecare and institutional benefits. Medicare is universal, but has limits. (E.g. home nursing care is free of charge, but skilled nursing care is only covered up to 20 days for $\$ 0$ OOP, $20-100$ days - $\$ 105$ per day, $101+$ days - user pays $100 \%$ of the cost). Medicaid is means-tested, and will require co-pay based on financial status of recipient. . Usage: $4.3 \%$ institutional / $2.8 \%$ home care $(1999 / 2000)$.

\section{A.3 Housing and Mortgage Markets}

These notes are a brief summary of ECB (2003) and is the starting point of our institutional analysis This information is not specific to retirees.

Spain, Netherlands and the UK have experienced two-digit growth rates in house prices in the 1990's; since 2002 (our data), Spain and the UK have as well. 2001-2002 saw rapid rise of house prices in Greece and Italy.

In many EU countries, tax policies are favorable to owner-occupied housing, while rental markets feature strict rent controls, which makes it favorable to be a long-term renter in particular, but may make the transition from homeownership to renting more difficult. Denmark, France, Sweden all have provisions to index rent to house pries or costs, which at least captures a trend above CPI. In other countries, rent controls make rents particularly of sitting renters be below market conditions. Denmark, France, Netherlands have high public ownership of rental property - around half of the rental market.

House buying: mortgage interest relief in Belgium, Denmark, Greece, Spain, Italy, Netherlands, Portugal, Sweden. The U.K. phased out mortgage interest relief in the 1990's. 
Ownership: property taxes in most places, though not Germany (there is land tax instead). Rates vary from $0.025 \%$ (Greece) to $1.5 \%$ (Austria) to much higher in France.

House selling: capital gains taxes everywhere, though generally excepted for long-term owner-occupiers (exemptions for those living over 5-10 years or reinvesting within 2 years).

Bequests: in addition to capital gains taxes, there are inheritance taxes - same as for financial assets in Belgium, Denmark and the UK; lower than financial assets in Germany; progressive between 0 and $65 \%$ in Greece, between 8 and 34\% in Spain, 5-40\% in France, 5-27\% in NL above threshold. Sweden taxes too. In Italy, the tax was abolished in 2001. If taxing at the same rate as financial assets, then makes little difference whether to inherit a house or financial assets.

Mortgage markets: home equity withdrawal has been significant in Denmark, Netherlands and UK. In Netherlands, the average LTV for a new mortgage loan is $112 \%$ (no legal limits on LTV). Denmark requires $20 \%$ downpayment on a new mortgage loan. UK average LTV is $30 \%$. All three have equity release products available. Among these, Netherlands and Denmark are among countries with high secured debt rates in our sample (around $40 \%$ at age 65, to $5 \%$ at 90). In Austria, average LTV is $60 \%$; in Germany, it is $60 \%$ by law. We observe, consistent with this, noticeably lower homeownership rates in these countries.

Countries with no equity release products/not permissible: Belgium, France (or not used), Italy. They are available but unusual in Spain, of very limited use in Greece, and restricted purpose-wise in Germany. 


\section{RECENT WORKING PAPERS FROM THE CENTER FOR RETIREMENT RESEARCH AT BOSTON COLLEGE}

Can Benefits and Work Incentives Counseling be a Path to Future Economic SelfSufficiency for SSI/SSDI Beneficiaries?

Zafar E. Nazarov, August 2013

How Do the Changing Labor Supply Behavior and Marriage Patterns of Women Affect Social Security Replacement Rates?

April Yanyuan Wu, Nadia S. Karamcheva, Alicia H. Munnell, Patrick Purcell, July 2013

Social Security and the 2001 Reform of the Railroad Retirement Program

Steven A. Sass, June 2013

An Assessment of the 2001 Reform of the Railroad Retirement Program

Steven A. Sass, June 2013

Reforming the Railroad Retirement System

Steven A. Sass, June 2013

How Do the Disabled Cope While Waiting for SSDI?

Norma B. Coe, Stephan Lindner, Kendrew Wong, and April Yanyuan Wu, June 2013

The Impact of Population Aging and Delayed Retirement on Workforce Productivity Gary Burtless, May 2013

Does Access to Health Insurance Influence Work Effort Among Disability Cash Benefit Recipients?

Norma B. Coe and Kalman Rupp, April 2013

How Will Older Workers Who Lose Their Jobs During the Great Recession Fare in the Long-Run?

Matthew S. Rutledge, Natalia Orlova, and Anthony Webb, March 2013

Can Long-Term Care Insurance Partnership Programs Increase Coverage and Reduce Medicaid Costs?

Wei Sun and Anthony Webb, March 2013

SSI for Disabled Immigrants: Why Do Ethnic Networks Matter?

Delia Furtado and Nikolaos Theodoropoulos, February 2013

The Use of VA Disability Benefits and Social Security Disability Insurance Among Veterans

Janet M. Wilmoth, Andrew S. London, and Colleen M. Heflin, February 2013

All working papers are available on the Center for Retirement Research website

(http://crr.bc.edu) and can be requested by e-mail (crr@bc.edu) or phone (617-552-1762). 